\title{
The Graft-Versus-Leukemia Effect in AML
}

\author{
Connor Sweeney ${ }^{1,2 *}$ and Paresh Vyas ${ }^{1,2}$ \\ ${ }^{1}$ MRC Molecular Haematology Unit, Oxford Biomedical Research Centre, MRC Weatherall Institute of Molecular Medicine, \\ University of Oxford, Oxford, United Kingdom, ${ }^{2}$ Department of Haematology, Oxford University Hospitals NHS Foundation \\ Trust, Oxford, United Kingdom
}

Allogeneic hematopoietic stem cell transplantation (allo-SCT) is the most established and commonly used cellular immunotherapy in cancer care. It is the most potent anti-leukemic therapy in patients with acute myeloid leukemia (AML) and is routinely used with curative intent in patients with intermediate and poor risk disease. Donor $\mathrm{T}$ cells, and possibly other immune cells, eliminate residual leukemia cells after prior (radio)chemotherapy. This immune-mediated response is known as graft-versusleukemia (GvL). Donor alloimmune responses can also be directed against healthy tissues, which is known as graft-versus-host disease (GvHD). GvHD and GvL often cooccur and, therefore, a major barrier to exploiting the full immunotherapeutic benefit of donor immune cells against patient leukemia is the immunosuppression required to treat GvHD. However, curative responses to allo-SCT and GvHD do not always occur together, suggesting that these two immune responses could be de-coupled in some

OPEN ACCESS

Edited by:

Antonio Curti,

University of Bologna, Italy

Reviewed by:

Yago Nieto

University of Texas MD Anderson Cancer Center, United States Alice Mims,

The Ohio State University United States

*Correspondence:

Connor Sweeney connor.sweeney@imm.ox.ac.uk

Specialty section:

This article was submitted to

Hematologic Malignancies, a section of the journal Frontiers in Oncology

Received: 22 August 2019 Accepted: 24 October 2019 Published: 19 November 2019

Citation:

Sweeney $C$ and Vyas $P$ (2019) The Graft-Versus-Leukemia Effect in AML.

Front. Oncol. 9:1217.

doi: 10.3389/fonc.2019.01217 patients. To make further progress in successfully promoting GvL without GvHD, we must transform our limited understanding of the cellular and molecular basis of GVL and GvHD. Specifically, in most patients we do not understand the antigenic basis of immune responses in GVL and GVHD. Identification of antigens important for GVL but not GvHD, and vice versa, could impact on donor selection, allow us to track GvL immune responses and begin to specifically harness and strengthen anti-leukemic immune responses against patient AML cells, whilst minimizing the toxicity of GvHD.

Keywords: acute myeloid leukemia, stem cell transplantation, graft-versus-leukemia, graft-versus-host disease $T$ cells, antigens

\section{INTRODUCTION}

Acute myeloid leukemia (AML) is the commonest aggressive leukemia in adults. It is the most frequent indication for allo-SCT, accounting for 36\% of transplants in Europe (1). Medically fit patients are treated with cytotoxic chemotherapy and are stratified according to their risk of relapse, which is based on genetic features of their leukemia and response to initial treatment. Approximately $70-80 \%$ of patients aged under 60 , and $50 \%$ of older patients, achieve a remission with induction chemotherapy $(2,3)$. Despite achieving a remission, without further treatment most patients would subsequently relapse, usually within 6 months, and relapse is associated with poor prognosis. Therefore, post-remission therapy aims to reduce relapse by eliminating residual leukemia cells (4).

Patients at higher risk of relapse receive an allo-SCT, which remains the most effective anti-leukemic curative treatment for the majority of AML patients with intermediate and poor risk disease (5). Prior to transplantation a patient receives conditioning, which consists of high doses of chemotherapy, with or without total body irradiation (TBI). Conditioning aims to kill 
cancerous cells but also reduces native bone marrow hematopoietic and immune cells. Subsequent transplantation of hematopoietic stem/progenitor and immune cells from a healthy donor leads to reconstitution of normal hematopoietic and immune cells. Crucially, alloreactivity of donor $\mathrm{T}$ cells against the patient's leukemia is responsible for the graft-versusleukemia (GvL) effect, which is a major mechanism for the curative effect of allo-SCT (6). However, this must be balanced against alloreactivity against normal tissues, which manifests as graft-versus-host disease (GvHD), a multi-system disorder that initially commonly affects the skin, gastrointestinal tract, liver, and lungs but later can affect almost any organ $(7,8)$.

Strategies to ameliorate the negative immunological effects include $\mathrm{T}$ cell depletion of grafts and treating recipients with immunosuppressive drugs (9). However, these can also dampen the desired anti-tumor $(\mathrm{GvL})$ responses, increasing the risk of relapse, and therefore a careful balance is required. After recovering from the toxicity of conditioning, if there is a concern about lack of a GvL response, for example due to loss of donor chimerism or evidence of molecular relapse, infusions of donor $\mathrm{T}$ cells can be administered as donor lymphocyte infusions (DLIs) in an attempt to produce a GvL response, with an associated risk of inducing GvHD $(10,11)$.

The overall survival (OS) of AML patients treated by alloSCT remains modest at $\sim 50 \%$ at 3 years, which is largely due to relapse and treatment-related mortality (GvHD and infection), emphasizing the need to improve upon current treatment approaches (12).

\section{HISTORICAL PERSPECTIVE}

Allo-SCT has been administered for over 50 years and remains the commonest and most effective cellular immunotherapy for myeloid malignancy. When first introduced, the aim of transplantation was to permit the delivery of high doses of chemotherapy that would otherwise be limited by toxicity to the native hematopoietic system. The first suggestion of a donor immune response against leukemia came in 1956 following mouse transplantation experiments, where murine leukemia relapses appeared to be reduced following transplantation with allogeneic bone marrow (from a different mouse strain) compared with the syngeneic marrow (same mouse strain) (13). Some of the animals treated with allogeneic transplantation died from a "wasting syndrome" with diarrhea that likely represented GvHD.

The first human allogeneic bone marrow transplantations were reported the following year by Thomas et al. (14). Six patients were treated with conditioning chemotherapy and radiotherapy, followed by an infusion of bone marrow from a healthy donor. Only two of the six patients showed evidence of engraftment and all died within 100 days of transplantation. Donors and patients were not matched for histocompatibility, as little was known about human histocompatibility antigens at this time.
The identification of human leukocyte antigens (HLA) and the development of methods to type these antigens enabled transplant programs to improve outcomes by patient-donor histocompatibility matching (15). The HLA locus is on the short arm of chromosome 6 and is one of the most polymorphic regions of the human genome. The polymorphic genetic diversity is an adaptive feature to facilitate presentation of the large repertoire of microbial antigens and is under host-pathogen coevolution (16). The first HLA antigen (HLA-A2) was discovered in 1958 by Jean Dausset, who studied the sera from patients who had received multiple blood transfusions (17). He found that sera from some of these patients agglutinated leukocytes from 11 of 19 individuals tested, but not leukocytes from the donor of sera, suggesting the presence of an alloantigen (18). Further HLA antigens were characterized in subsequent years by Thorsby (18), van Rood et al. (19), and Payne et al. (20). The clinical importance of HLA matching in kidney transplantation was realized during the 1960s. Grafts between unrelated individuals are associated with a high likelihood of major incompatibility due to the polymorphic nature of the HLA locus. However, within a family there are only 4 haplotypes (2 from each parent). In 1965, Terasaki and colleagues reported improved kidney graft survival from HLA-matched donors and by the early 1970s it was evident that kidneys transplanted between HLA-identical siblings was the optimal combination (18).

In 1965, Mathé reported histocompatibility testing of bone marrow donors for a patient with acute lymphoblastic leukemia (ALL) (21). The patient was given grafts from six family members and developed a "secondary syndrome," later to be described as GvHD, involving the skin, gastrointestinal tract, and liver. Six months after the transplant, further bone marrow was administered with the aim of enhancing the immune response against leukemia. In order to choose the donor least likely to reactivate a secondary syndrome, histocompatibility testing was performed by giving the patient skin grafts from each donor. The donor was selected whose skin graft was not rejected, but this still led to a steroid-responsive "secondary syndrome" (22).

The development of techniques to type HLA in patients and donors in the mid/late 1960s enabled E. Donnall Thomas to open an allogeneic bone marrow transplantation program in Seattle using HLA-matched donors for patients with acute leukemia. In 1977, they reported 100 transplantations for relapsed and refractory acute leukemia, using chemotherapy and radiation therapy conditioning (23). HLA matching was performed using mixed leukocyte culture and all transplants used HLA-identical related donors. Although only 13 patients were disease free after 1-4.5 years follow-up in this case series, administering transplantation earlier in the course of AML resulted in a cure rate of $50 \%$ in patients transplanted in first remission (24). Crucially, Thomas appreciated that the donor immune system likely plays a key role in eliminating residual leukemia cells. Although survival was reduced in patients with severe GvHD, most patients did not die of relapse. Furthermore, patients with GvHD relapsed later than those without GvHD $(23,25)$. In 1990, E. Donnall Thomas won a Nobel Prize for his discoveries concerning cell transplantation in the treatment of human disease. 


\section{DONOR SELECTION}

Despite being the preferred donor, a HLA-matched sibling is available for only $30 \%$ of patients. The use of HLA-matched unrelated donors for stem cell transplantation drastically increased the number of patients who could be treated (26). Although the HLA locus is highly polymorphic, haplotypes are conserved in populations due to linkage disequilibrium. In the years after the first unrelated donor transplant, donor registries were established, but due to large variation in ethnic representation, the chance of finding a full HLA match varied widely according to ethnicity (27). Therefore, international collaboration has been essential for the establishment of a global donor registry. The International Bone Marrow Transplant Registry (IBMTR) was founded in 1972 to record transplant outcome data. In 1974, the European Group for Blood and Marrow Transplantation (EBMT) was formed and in 1988 Bone Marrow Donors Worldwide was established. There are currently over 34 million registered donors worldwide and almost 800,000 cord blood units (28). Although a donor will be found for most patients, a high resolution HLA-matched donor will not be available for all, in particular for patients that are not of white European descent, as the ethnic diversity of patients is not reflected in donor registries (29).

In the absence of a HLA-matched donor, the use of alternative donor allo-SCTs has increased the pool of available donors. This involves either a HLA-mismatched unrelated donor, haploidentical related donor or an umbilical cord blood transplant. Mismatched allo-SCTs generally have a mismatch at 1 or 2 HLA alleles (HLA-A, -B, -C, -DRB1, or -DQB1), as a greater degree of mismatch is associated with unacceptably high risks of GvHD and non-relapse mortality (15).

Haploidentical related donor transplants are from siblings, parents or children of the patient who share at least $50 \%$ of HLA alleles. As most patients have at least one haploidentical first-degree relative, this approach has enabled a donor to be found for almost all patients, which is particularly important for ethnic minority groups that are under-represented in donor registries. Due to bidirectional alloreactive $\mathrm{T}$ cell responses, the first haploidentical transplants were associated with high mortality from GvHD and also a host-versus-graft reaction that resulted in rejection of transplanted cells (30). Improvement in $\mathrm{T}$ cell depletion methods have reduced GvHD and graft failure following haploidentical allo-SCT. In 2005, a phase II study of 101 patients treated with haploidentical allo-SCT used positive selection for $\mathrm{CD}_{3} 4^{+}$cells to $\mathrm{T}$ cell deplete grafts and administered high doses of $\mathrm{CD} 34^{+}$stem cells to recipients. They reported engraftment in $93 \%$ of patients, acute GvHD in $8 \%$ and chronic GvHD in $7 \%$ of evaluable patients. However, $36.5 \%$ of patient died of non-relapse causes, mainly due to infection (31). This highlights a major challenge of administering haploidentical allo-SCT. Although intensive conditioning of the recipient and $\mathrm{T}$ cell depletion of the graft improves GvHD and hematopoietic engraftment, immune reconstitution is poor, leading to opportunistic infections. Nevertheless, outcomes following haploidentical allo-SCT have improved with refinements in $\mathrm{T}$ cell depletion, including the use of cyclophosphamide in a narrow time window posttransplantation (32). The use of haploidentical transplants has been increasing in recent years and EBMT reported that $14.7 \%$ of allo-SCTs in 2017 used haploidentical donors (33).

Umbilical cord blood transplantation is an alternative source of hematopoietic stem cells for transplantation. Naivety of immune cells in cord blood permits less stringent HLA matching. However, due to the relatively low number of stem cells in a unit, adult transplants require either two cord units or ex vivo expansion of stem cells. Furthermore, the naivety of immune cells leads to an increase in opportunistic infections. As the use of haploidentical donors has increased, cord blood transplants have reduced and 2\% of allo-SCTs reported by EBMT in 2017 used cord blood donations (33).

\section{ALLOGENEIC STEM CELL TRANSPLANTATION FOR AML}

Although allo-SCT reduces relapse, non-relapse mortality due to complications of the transplant including GvHD and infection will counterbalance this beneficial effect in many patients. Therefore, when deciding which individuals will benefit from allo-SCT, there must be a patient-specific evaluation. The European LeukemiaNet (ELN) AML Working Party proposes a dynamic risk assessment that integrates the cytogenetic and molecular genetic features of AML at diagnosis with the patient's response to induction therapy to estimate the risk of relapse after consolidation treatment with either allo-SCT or chemotherapy. This relapse risk is balanced against the non-relapse mortality from allo-SCT that is estimated using the patient's co-morbidities with the hematopoietic cell transplantation comorbidity index, HCT-CI (34) (Table 1). The ELN suggest that if, based on an individual's risk assessment, the disease-free survival is predicted to improve by at least $10 \%$, allo-SCT should be recommended. In the absence of significant co-morbidities, this translates to intermediate and poor risk patients.

The ELN genetic risk stratification has been refined in recent years, reflecting a deeper understanding of the genomic landscape of AML, and mutations in genes such as RUNX1, ASXL1, and TP53 now contribute to the adverse risk category (36, 37). Assessment of post-treatment minimal residual disease (MRD) provides additional prognostic information that complements pre-treatment genetic risk stratification. The presence of low amounts of MRD has been consistently associated with increased relapse and reduced OS in AML (38). Two approaches may be used for MRD detection: (1) multiparameter flow cytometry, and (2) molecular techniques, including real-time quantitative PCR (RT-qPCR) and next generation sequencing (NGS). MRD using flow cytometry commonly involves the identification of a leukemia-associated immunophenotype for the individual patient that differs from normal hematopoietic cells (39). RT-qPCR assays are available for MRD detection of specific genetic lesions found in sub-groups of patients with AML, including NPM1 mutations, CBFB-MYH11, RUNX1-RUNX1T1, and BCR-ABL1 fusion genes. As a molecular marker can be detected in the majority of cases, NGS offers the 
TABLE 1 | European LeukemiaNet (ELN) recommendations for allogeneic stem cell transplantation in patients with AML in first complete remission.

\begin{tabular}{|c|c|c|c|c|c|}
\hline \multirow[t]{2}{*}{$\begin{array}{l}\text { AML risk } \\
\text { group }\end{array}$} & \multirow[t]{2}{*}{ Risk assessment } & \multicolumn{2}{|c|}{$\begin{array}{l}\text { Risk of relapse following } \\
\text { consolidation treatment }\end{array}$} & \multicolumn{2}{|c|}{$\begin{array}{l}\text { Non-relapse mortality risk that would indicate } \\
\text { allo-SCT as consolidation treatment }\end{array}$} \\
\hline & & $\begin{array}{l}\text { Chemotherapy* } \\
(\%)\end{array}$ & Allo-SCT (\%) & $\begin{array}{l}\text { HCT-Cl } \\
\text { score }\end{array}$ & $\begin{array}{l}\text { Non-relapse } \\
\text { mortality (\%) }\end{array}$ \\
\hline Good & $\begin{array}{l}t(8 ; 21) \text { with WBC } \leq 20 \\
\text { Inv }(16) / t(16 ; 16) \\
\text { Mutated CEBPA (bi-allelic) } \\
\text { Mutated NPM1 (No FLT3-ITD } \\
\text { mutation) } \\
\text { Early first complete remission (after } \\
\text { first cycle of chemotherapy) and } \\
\text { MRD negative }\end{array}$ & $35-40$ & $15-20$ & 0 & $10-15$ \\
\hline Intermediate & $\begin{array}{l}t(8 ; 21) \text { with WBC }>20 \\
\text { Cytogenetically normal (or loss of } X \\
\text { and } Y \text { chromosomes), WBC count } \\
\leq 100 \text { and early first } \\
\text { complete remission }\end{array}$ & $50-55$ & $20-25$ & $\leq 2$ & $<20-25$ \\
\hline Very poor & $\begin{array}{l}\text { Monosomal karyotype } \\
\text { Abn3q26 } \\
\text { Enhanced Evi-1 expression }\end{array}$ & $>90$ & $40-50$ & $\leq 5$ & $<40$ \\
\hline
\end{tabular}

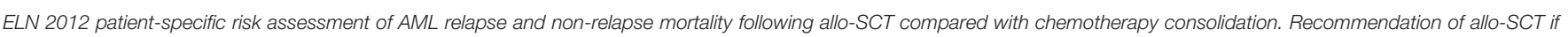

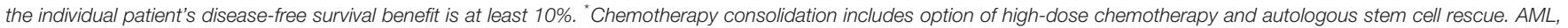

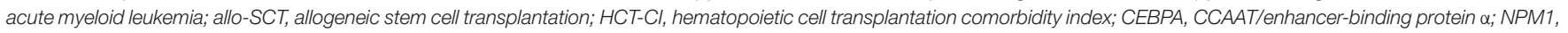

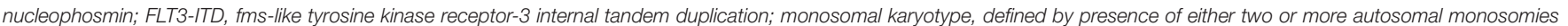

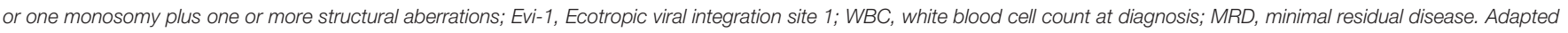
from Cornelissen et al. (35).

possibility of tracking additional molecular markers in the future. However, validation of markers is still required, as mutations in genes associated with pre-leukemic clones (e.g., DNMT3A, TET2, and ASXL1) are frequently detected at remission but are poorly predictive of relapse (40). A key goal is to be able to use MRD data to identify early recurrence of leukemia and guide postremission therapy. This could offer the opportunity to intervene pre-emptively to prevent morphological relapse, such as by administering further pre-transplant chemotherapy, increasing the intensity of the transplant conditioning or introducing posttransplant therapy (37). However, the optimal means of using MRD to guide treatment decisions has yet to be fully defined.

When treating relapsed AML with curative intent, allo-SCT is generally the most effective therapy. However, compared to transplants in first remission, outcomes are inferior due to an increase in both relapse (40-45\%) and non-relapse mortality (25$35 \%$ ) (35). Breems et al. developed a prognostic index for AML patients at first relapse based on a study of 667 patients to predict clinical outcomes (41). Three risk groups were defined using four clinical parameters: duration of remission, age at relapse, cytogenetics at diagnosis and whether patients had previously received an allo-SCT. Only $37 \%$ of patients in the cohort entered a second complete remission and $18 \%$ received an allo-SCT after relapse. However, in all risk groups, patients who received allo-SCT had superior outcomes.

\section{EVIDENCE FOR A GVL EFFECT}

A range of donor immune cells are likely to contribute to the GvL response, including $\mathrm{T}$ cells, NK, and $\mathrm{B}$ cells. However, current clinical evidence suggests that $\mathrm{T}$ cells exert the most potent and clinically relevant anti-leukemic effect. Donor $\mathrm{T}$ cells recognize leukemia through interactions between their $\mathrm{T}$ cell receptor and major histocompatibility (MHC) molecules on the surface of AML cells. MHC, which are known as human leukocyte antigens (HLA) in humans, present peptides to T cells. HLA class I molecules are expressed on all nucleated cells and present peptides to $\mathrm{CD} 8^{+} \mathrm{T}$ cells, whereas class II molecules are primarily expressed on specialized antigen presenting cells and present peptides to $\mathrm{CD}^{+}{ }^{+} \mathrm{T}$ cells. High levels of HLA class II expression is also seen in most cases of AML (42-44).

When hematopoietic allogeneic stem cell transplantation is planned, a donor is sought with HLA alleles matching the recipient. This reduces immune responses from patient-derived cells, which could result in graft rejection, and from donorderived cells, which result in GvHD. However, even after a HLA-matched transplant, an immune response against leukemia occurs. The importance of this GvL response in disease control in AML is evidenced by several clinical observations:

1. An inverse correlation between GvHD and disease relapse.

2. Increased relapse in patients treated with $\mathrm{T}$ cell depleted grafts. 
3. The successful use of DLIs post-transplantation to achieve disease control.

4. Cure of patients treated with reduced intensity conditioning (RIC) regimens that permit stable engraftment of donor hematopoietic cells, but are unlikely to directly kill all leukemia cells (45).

5. Immune evasion mechanisms displayed by AML at posttransplant relapse indicate the presence of immune selection.

\section{GvHD and Relapse}

Many retrospective analyses of patients who received alloSCT for hematological malignancies have found a significant association between incidence of GvHD and reduced relapse rates (46-49). Following transplantation for AML, Baron et al. found that grade I acute GvHD is associated with lower incidence of relapse (hazard ratio 0.7) and there was a trend toward an OS benefit. However, severe acute GvHD (grade III and IV) was associated with a worse OS due to non-relapse mortality. Similarly, the extent of chronic GvHD correlated with lower relapse rates but increased non-relapse mortality (48). Recipients of identical twin (syngeneic) stem cell transplants have a higher incidence of relapse but a lower treatment-related mortality due to a reduction in GvHD (46).

A retrospective study of 48,111 allo-SCTs performed in adult patients between 1998 and 2007 for a range of hematological malignancies highlighted that GvHD is strongly associated with a GvL effect in CML and ALL, with GvL effect inferred from post-transplant relapse rates. In contrast, there was a weaker correlation between the GvL effect and GvHD in AML and myelodysplastic syndrome (MDS) $(45,50)$. This suggests that some mechanisms of GvL may be distinct from GvHD and provides hope that these processes may be uncoupled therapeutically (Figure 1).

Studies comparing outcomes of AML patients treated with sibling or matched unrelated donor transplants have yielded conflicting results, with some reporting inferior survival with unrelated donors and others detecting no significant survival difference (51-53). Although a more potent GvL effect may be expected with HLA-matched unrelated vs. related donors, studies have failed to demonstrate a reduction in relapse following unrelated donor transplants $(52,54)$. It is possible that high resolution HLA typing and advances in supportive care have improved the outcomes of matched unrelated transplants in recent years by reducing transplant mortality (55). However, 7/8 mismatched unrelated donor transplants are associated with increased early mortality, but beyond 6 months survival rates are similar between donor types (56).

The most common source of donor stem cells is peripheral blood, which accounts for $81 \%$ allo-SCTs for AML in Europe (1). Donors are treated with recombinant human granulocyte colony stimulating factor (G-CSF) and sometimes with the CXCR4 antagonist plerixafor prior to harvesting by apheresis (57). A bone marrow harvest is performed less commonly, by aspirating marrow from the pelvis, usually while the donor is under general anesthetic. Some studies indicate a survival advantage using peripheral blood stem cell (PBSC) compared with bone marrow for treatment of malignant disease $(58,59)$, whereas others have

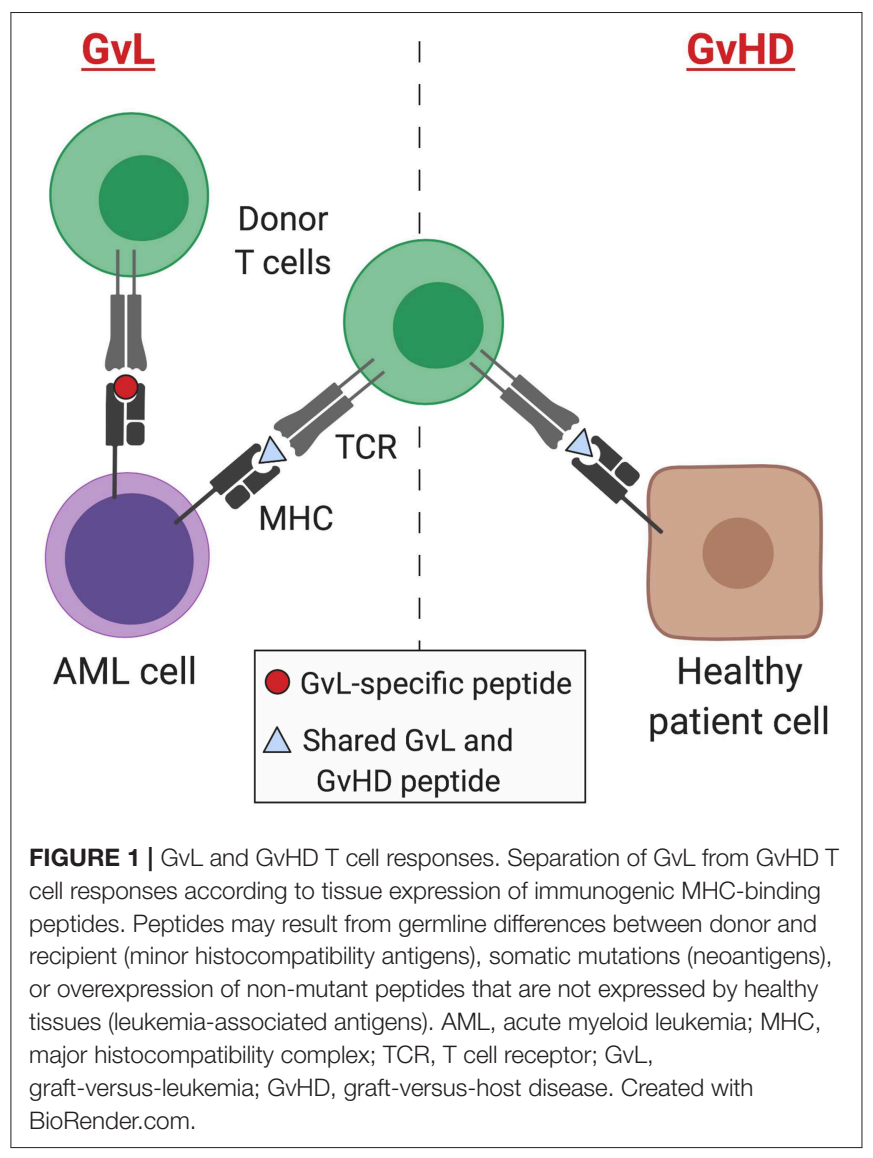

shown no impact on OS $(60,61)$. PBSC transplants have a higher $\mathrm{T}$ cell content and have been consistently associated with more rapid neutrophil and platelet engraftment. Lower relapse rates, suggestive of a GvL effect, was observed in a large randomized trial of PBSC vs. bone marrow donation for hematological malignancy (59). However, other studies have shown no effect. Consistent with the higher T cell content of PBSC grafts, a higher incidence of chronic GvHD has been consistently reported across studies and some studies also report an increase in acute GvHD (58-61). Therefore, peripheral blood is more commonly used as the source of stem cells in the treatment of hematological malignancy due to the potential for a more potent GvL effect and the avoidance of general anesthetic risks for the donor. In contrast, bone marrow harvest is generally preferred for the treatment of non-malignant conditions due to the reduced incidence of GvHD and the absence of benefit conferred by the higher number of alloreactive T cells in a PBSC graft (1).

\section{T Cell Depletion and Relapse}

The commonest causes of death after allo-SCT for leukemia are relapse followed by GvHD (62). The role of $\mathrm{T}$ cells in GvHD was established in 1968 by van Dicke and colleagues, who used a murine transplantation model to show that mice transplanted with lymphocyte-depleted spleen fractions survived without GvHD, whereas mice receiving lymphocyte-replete fractions all died from GvHD (63). When introduced in human 
TABLE 2 | Methods of T cell depletion.

\begin{tabular}{ll}
\hline Depletion strategy & Method \\
\hline $\begin{array}{l}\text { Ex vivo } \\
\text { Positive selection } \\
\text { Negative selection: } \\
\text { Pan-T cell }\end{array}$ & CD34 selection \\
& CD3 depletion \\
T cell subset & Monoclonal anti-CD52 (Alemtuzumab) \\
& CD8 depletion \\
& CD3/CD19 depletion \\
In vivo & $\alpha \beta$ T cell/CD19 depletion \\
Pre-transplant conditioning & Monoclonal anti-CD52 (Alemtuzumab) \\
& Polyclonal anti-thymocyte globulin (ATG) \\
& Atgam ${ }^{\circledR}$ (horse) \\
Post-transplant & Thymoglobulin (rabbit) \\
\hline
\end{tabular}

Depletion of T cells may be achieved by manipulating the stem cell graft ex vivo or by administering treatment to the transplant recipient in vivo.

transplants, it was hoped that performing T cell depletion would reduce morbidity and mortality from GvHD and also eliminate the requirement for post-transplant treatment of patients with cyclosporin/methotrexate immunosuppression. Whilst a low incidence of GvHD was confirmed with T cell depleted grafts, there was an increase in graft failure and disease relapse (64).

An early strategy for ex vivo $\mathrm{T}$ cell depletion of grafts was incubation with Campath- $1 \mathrm{H}$ (alemtuzumab), the first humanized monoclonal antibody, together with complement from donor serum (Table 2) $(65,66)$. Although this reduced the incidence of GvHD in patients transplanted for chronic myeloid leukemia (CML), the incidence of relapse approximately doubled (67). Similarly, early experience in AML transplants found an increase in relapse with T cell depletion $(46,68)$. Marmont et al. studied 1154 AML found a 2.75-fold increased risk of relapse following $\mathrm{T}$ cell depletion. An increased incidence of graft failure was observed in both matched related and unrelated donor transplants, suggesting that donor $\mathrm{T}$ cells might be required to counterbalance the effect of recipient $\mathrm{T}$ cells rejecting the graft (69). These findings suggested that ex vivo pan-T cell depletion strategies are not optimal even for unrelated donor transplantation (70). An alternative method of T cell depletion uses $\mathrm{CD}_{3}{ }^{+}$selection of G-CSF-mobilized PBSCs, which results in $4-5 \log _{10}$ reduction in T cells (9). Due to significant reduction in GvHD, this strategy has enabled the transplantation of older patients. Despite concerns about increased relapse due to a reduction in donor T cells available for a GvL effect, this was not seen in a study of AML patients (71).

Other methods of negative selection have been used to balance beneficial effects of donor $\mathrm{T}$ cells (a GvL effect and improved engraftment) against GvHD. Treatment of 41 patients with $\mathrm{CD}^{+}$depleted grafts led to engraftment of all recipients. However, GvHD risk was not reduced, with $61 \%$ grade IIIV reported, implying that other immune cell populations are also likely to be important for GvHD such as $\mathrm{CD} 4^{+} \mathrm{T}$ cells or NK cells (72). Combined elimination of T cells and B cells by targeting $\mathrm{CD}^{+} / \mathrm{CD} 19^{+}$has been used to eliminate both $\mathrm{T}$ cells that are responsible for GvHD and B cells that can lead to post-transplant lymphoproliferative disorders. $\mathrm{CD} 3^{+} / \mathrm{CD} 19^{+}$ depletion was used in a study of 61 recipients of haploidentical transplants who lacked a HLA-matched donor. In this cohort of high-risk patients, $62 \%$ had AML and the incidence of grades IIIV acute GvHD and chronic GvHD were 46 and 18\%, respectively and incidence of relapse was 31\% (73).

The majority (95\%) of circulating T cells have $\mathrm{T}$ cell receptors that comprise dimers of $\alpha$ and $\beta$ glycoproteins and are implicated in the adaptive immune response that mediates GvHD and GvL. In contrast, $\gamma \delta \mathrm{T}$ cells are part of the innate immune system and pre-clinical models have indicated they do not cause GvHD but promote alloengraftment (74). Given the protective role for $\gamma \delta \mathrm{T}$ cells, there has been interest in specific $\alpha \beta \mathrm{T}$ cell depletion. Reduction in acute leukemia relapse was observed among recipients of $\alpha \beta$-depleted haploidentical donor grafts compared with pan-CD3 depletion (75). The level of circulating $\gamma \delta \mathrm{T}$ cells post-transplant correlates significantly with relapsefree survival, suggestive of a GvL effect (76). Furthermore, several subsequent studies have demonstrated anti-tumor activity of $\gamma \delta$ $\mathrm{T}$ cells against leukemia and other cancers, highlighting their protective role $(70,77,78)$.

An alternative approach is to $\mathrm{T}$ cell deplete in vivo by treating the recipient with either alemtuzumab (79) or anti-thymocyte globulin (ATG) (80) as part of pre-transplant conditioning, or by treating with post-transplant cyclophosphamide (81). Alemtuzumab-containing regimens are consistently associated with a reduction in acute and chronic GvHD (82). Malladi et al. retrospectively studied $88 \mathrm{AML}$ patients treated with HLA-identical sibling transplants, with or without alemtuzumab conditioning. A significant reduction in chronic GvHD was seen and a trend toward increased relapse (35\% with alemtuzumab and $19 \%$ in the untreated group) (83). Furthermore, due to more pronounced immunosuppression compared with ATG, alemtuzumab is more commonly associated with reactivation of cytomegalovirus (CMV) and Epstein Barr virus (EBV) $(82,84)$.

High-dose cyclophosphamide administered early posttransplantation depletes alloreactive $\mathrm{T}$ cells derived from host and donor. This approach has grown in popularity, particularly in the haploidentical allo-SCT setting, due to its efficacy at reducing GvHD and graft failure (32). Cyclophosphamide selectively targets highly proliferative alloreactive $\mathrm{T}$ cells early post-transplant, while sparing the relatively quiescent nonalloreactive $\mathrm{T}$ cell and hematopoietic stem cell compartments (27). Ciurea et al. reported a non-randomized comparison of 65 haploidentical transplants: $\mathrm{T}$ cell replete bone marrow transplants treated with post-transplant cyclophosphamide vs. T cell depleted PBSC transplants without post-transplant immunosuppression. A significant reduction in chronic GvHD was observed in the $\mathrm{T}$ cell replete group (8 vs. 18\%) with an associated reduction in non-relapse mortality (16 vs. $42 \%)$ and increase in OS at 1-year post-transplant (66 vs. 30\%). Improved reconstitution of $\mathrm{T}$ cell subsets and a concomitant reduction in infectious complications was also observed in the $\mathrm{T}$ cell replete 
group (85). Following its success in haploidentical allo-SCT, post-transplant cyclophosphamide has been demonstrated to provide effective GvHD prophylaxis and a good safety profile in the HLA-matched related and unrelated donor settings (86).

$\mathrm{T}$ cell depletion has been essential in enabling allo-SCTs to be delivered outside of the HLA-matched sibling setting, where the risk of GvHD would be otherwise high, such as mismatched sibling, unrelated donor and haploidentical settings. A balanced approach to $\mathrm{T}$ cell depletion is needed, tailored to the GvHD risk associated with the type of donor, and the post-transplant immunosuppressive therapy used.

\section{DLIs Reinstate a GvL Effect}

Given the crucial role of a donor immune response in preventing relapse, in 1989 prophylactic infusions of donor lymphocytes were trialed immediately after transplant in AML patients in an attempt to establish a GvL response (87). However, acute GvHD and mortality was increased. Subsequent work in the 1990s on CML established that using the original transplant donor and separating DLI from the transplant by at least 2 months produced complete hematological, cytogenetic and molecular remissions, indicating a robust GvL effect, often without accompanying GvHD $(88,89)$. Of relapses, $67 \%$ achieved molecular remission following DLI and this translated into 95\% 3-year survival. However, transplantation for CML in the current era has been marginalized by targeted tyrosine kinase inhibitor treatment, which is highly efficacious while sparing patients the toxicity of transplantation.

Patients with AML or MDS have a lower response rate to DLI at $20-40 \%(90,91)$. A large retrospective analysis by EBMT of 399 post-transplant AML relapses, of whom $43 \%$ were treated with DLIs, showed a survival advantage at 2 years with DLI treatment (21\% with DLIs vs. $9 \%$ without) (92). Although a GvL effect is evident from DLIs in AML, efficacy has been limited to patients with favorable cytogenetics or a low disease burden at relapse. AML cells are highly proliferative, which may cause them to rapidly overwhelm the ability of donor $\mathrm{T}$ cells to exert immunological control in the presence of abundant disease.

Given that DLIs are most likely to exert a therapeutic effect with lower AML disease burden, there has been significant interest in incorporating prophylactic DLI into transplant regimens. For patients with high risk AML, the FLAMSA regimen incorporated prophylactic DLI. It consists of cytoreduction with fludarabine, cytarabine, and amsocrine followed by either 4 Gy TBI or busulphan conditioning, ATG and cyclophosphamide. Prophylactic DLI was given in a nonrandomized study at day +120 in patients who were not receiving immunosuppression who were free from GvHD (93). Longterm follow-up revealed that at 7 years post-transplant, there was a significant survival advantage of DLI, with OS 67\% compared with $31 \%$ in a non-randomized control group (94). A phase II randomized trial of prophylactic DLI post-transplant in high risk myeloid malignancy is currently underway (PRO-DLI, NCT02856464) (95).

\section{Cure of Patients Treated With RIC Conditioning}

Given that the median age of AML diagnosis is 65-70, delivery of transplants with myeloablative conditioning would be associated with unacceptably toxicity and high transplant-related mortality in the majority of patients (4). The development of RIC protocols has enabled allo-SCT to be delivered to older patients. This is particularly important because higher risk cytogenetic and molecular genetic features are commoner in older people and so this cohort would have a limited prognosis if treated with chemotherapy alone.

Myeloablative conditioning regimens use alkylating agents, with or without TBI, at doses predicted to prevent autologous hematopoietic recovery. In RIC regimens, doses of alkylating agents or TBI are reduced by at least 30\% (96). RIC must be sufficiently intense to prevent graft rejection by host hematopoietic cells, but preserve a GvL effect, which is especially important in given that leukemia cells are unlikely to be entirely eliminated by the conditioning. A large retrospective analysis of 1,070 AML and MDS patients who received a RIC transplant in first complete remission demonstrated that this treatment can be safely delivered to older adults. The 2-year OS in AML patients aged 65 years or older was $36 \%$, which was not significantly different to survival of younger adults in a multivariate analysis (97). Overall, compared with myeloablative transplants, most data show increased relapse following RIC conditioning, but this is likely to be offset by a reduction in non-relapse mortality, particularly in older adults (98).

\section{Immune Evasion Mechanisms at Post-transplant Relapse}

$\mathrm{T}$ cells play a major role in shaping the immunogenicity of cancers, which can lead to tumor cells altering their phenotype such that they are no longer controlled by the immune system, in a process known as "immunoediting" (99). Loss of AML immunogenicity under donor immune selective pressure has been shown to lead to immune escape and relapse. There are multiple possible mechanisms that may be used by AML to evade the GvL response (Figure 2).

\section{Reduction in HLA Presentation}

Following haploidentical transplantation for AML or MDS, disease from 5 of 17 patients who relapsed had genomic loss of the mismatched HLA haplotype due to acquired uniparental disomy of chromosome $6 \mathrm{p}(100)$. This suggests that in these patients, major HLA mismatches were the critical targets of the GvL response and loss of mismatched HLA as a single large-scale genetic event was sufficient to evade immune detection. Genomic HLA loss has also been described following HLA-matched alloSCT for AML $(101,102)$. In a recent study of relapsed AML in 12 recipients of matched unrelated donor transplants, 2 patients were found to have focal deletions spanning HLA class I alleles. Given that HLA alleles were identical in patient and donor, it is likely that the pivotal GvL targets were peptide(s) presented by HLA. In this setting, loss of the HLA locus prevented these key peptides being presented to donor-derived T cells (102). 


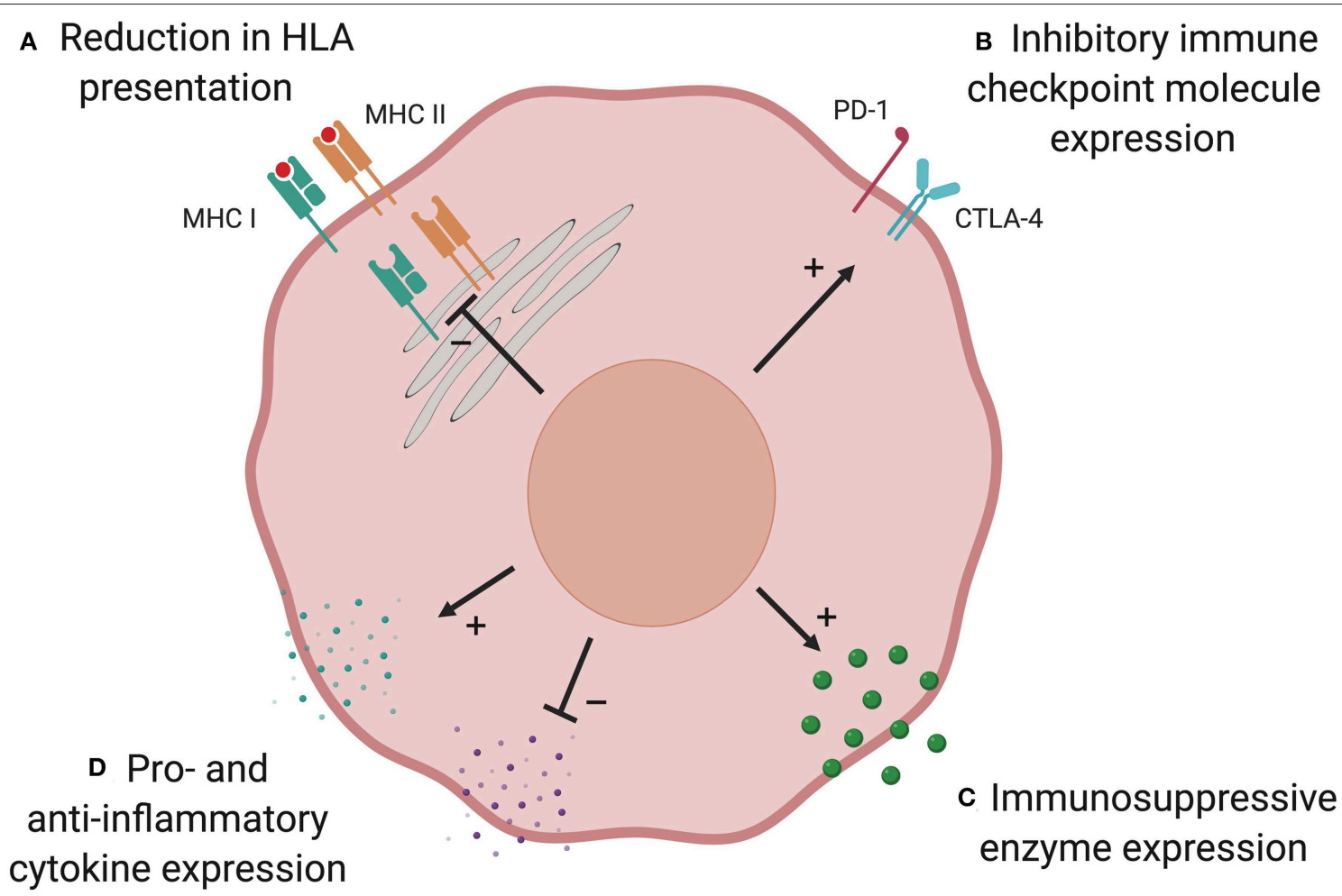

FIGURE 2 | Possible mechanisms of post-transplant immune evasion. Loss of AML immunogenicity under immune selective pressure following allo-SCT leads to immune escape and relapse. There are multiple possible mechanisms: (A) Reduction in HLA presentation prevents donor-derived T cells identifying the AML cell. This is commonest in HLA-mismatched transplants and can result from genetic loss of part, or all, of the HLA locus. In other patients, downregulation of HLA expression via defects in transcriptional regulators may play a role. (B) Upregulation of immune checkpoint inhibitory molecules has been shown to suppress $T$ cell responses at relapse in a subset of patients. Expression of anti-inflammatory enzymes (C) and cytokines, and suppression of pro-inflammatory cytokines (D), have an

immunosuppressive effect in AML but their role is yet to be established in the allo-SCT setting. Created with BioRender.com.

Recent studies have shown that patients with relapsed AML post-allo-SCT have dysregulation of pathways that influence immune function, including downregulation of the expression of HLA class II genes and associated transcriptional regulators $(43,44)$. Transcriptional downregulation of genes involved in antigen processing and HLA presentation, such as IFI30, HLA$D M A, H L A-D M B$, and $C D 74$, were observed at relapse in patients with reduced HLA class II expression. In contrast with genetic loss of HLA, reduction in HLA class II expression did not correlate with the number of donor-recipient HLA mismatches and also occurred after HLA-matched transplants, where it may favor immune evasion by substantially narrowing the repertoire of antigens presented to donor-derived $\mathrm{T}$ cells. Given that immune evasion mechanisms have involved genomic loss or transcriptional downregulation of both HLA class I and II molecules, roles for $\mathrm{CD}^{+}$as well as $\mathrm{CD}^{+} \mathrm{T}$ cells in $\mathrm{GvL}$ responses are likely.

\section{Immune Checkpoint Molecule Expression}

The balance of co-stimulatory and co-inhibitory signals conveyed to $\mathrm{T}$ cells influences whether the cell becomes activated when its $\mathrm{T}$ cell receptor binds its cognate HLA-peptide complex. Upregulation of co-inhibitory signaling has been described in many cancers, including AML, and can result in a dysfunctional "exhausted" $\mathrm{T}$ cell state $(103,104)$. In AML patients, $\mathrm{CD}^{+}$cytotoxic T-cells expressing co-inhibitory receptors are functionally impaired and predict AML relapse (105). Toffalori et al. demonstrated an increase in co-inhibitory ligand expression (PD-L1 and $\mathrm{B} 7-\mathrm{H} 3$ ) at post-transplant relapse compared with paired diagnostic samples, with a concomitant increase in the corresponding receptors on $\mathrm{T}$ cells (44). Increased expression of co-inhibitory ligands and their receptors was mutually exclusive with downregulation of HLA class II, indicating distinct mechanisms of post-transplant immune evasion. Together, these modalities accounted for over two-thirds of relapses.

\section{Immunosuppressive Enzymes}

Expression of metabolic enzymes by AML, such as arginase II (106) and indoleamine 2,3-dioxygenase 1 (IDO1) (107), has been shown to provide an immunosuppressive environment. AML blasts express and secrete arginase II, resulting in significantly elevated plasma levels and enhanced arginine metabolism compared with healthy controls. This is associated with impaired $\mathrm{T}$ cell proliferation and an immunosuppressive M2-like monocyte phenotype (106). IDO1 is an interferon 
(IFN)- $\gamma$-inducible enzyme that metabolizes tryptophan, leading to kynurenine production. Kynurenine inhibits effector $\mathrm{T}$ cell function and promotes the differentiation of immunosuppressive regulatory T cells (Tregs). Correspondingly, IDO1 expression by pediatric AML cells was associated with significantly worse 8 -year event free survival (16.4\%) than non-expressing AMLs (48.0\%) (107). Although these mechanisms have not been demonstrated in the allo-SCT setting, they could play a role in suppressing alloimmune GvL responses (108).

\section{Alteration of Pro-and Anti-inflammatory Cytokines}

A potential method of immune evasion following allo-SCT is the modulation of pro- and anti-inflammatory cytokines. Suppression of pro- and elevation in anti-inflammatory cytokines are predicted to dampen effective GvL responses, though this has not been proven. AML cells express anti-inflammatory cytokines interleukin-4 (IL-4) and IL-10, both of which are known to reduce HLA class II expression $(108,109)$. This mechanism has been shown to promote immune evasion in a mouse model of chronic lymphocytic leukemia (CLL) (110).

Conversely, pro-inflammatory cytokines could promote GvL responses and therefore suppression of these cytokines might be used by leukemia cells to evade alloreactivity. IL-15 is a pro-inflammatory cytokine expressed by multiple cell types, including dendritic cells and myeloid progenitors (111). Reduced plasma levels early post-transplant is significantly associated with relapse, indicating reduced immune control of disease (112). Furthermore, treatment of AML harboring the internal tandem duplication in the gene encoding Fms-related tyrosine kinase 3 (FLT3-ITD) with the tyrosine kinase inhibitor, sorafenib, increases IL-15 expression in human AML. In a mouse model of AML with FLT3-ITD, sorafenib treatment promotes a GvL effect through IL-15 production (113). A recent phase 1 trial evaluated the IL-15 superagonist complex, ALT-803, in patients with hematological malignancies who relapsed after allo-SCT. Responses were observed in 19\% of evaluable patients with expansion and activation $\mathrm{CD} 8^{+} \mathrm{T}$ cells and NK cells, without an increase in Tregs (114). Further study is required to demonstrate whether therapeutic modulation of cytokines can enhance clinically relevant GvL effects and reduce relapse.

\section{CANDIDATE GVL ANTIGENS}

Genetic differences between donor and recipient are crucial for a GvL effect, as is evident from the increased relapse rate seen in syngeneic twin transplants (46). When allo-SCT is planned, a donor is sought with human lymphocyte antigens, HLA-A, -B, $-C$, -DRB1, and -DQB1 alleles matching the recipient to reduce the risk of GvHD. Often HLA-DPB1 is not taken into account when selecting donors, as OS is unaffected by mismatching HLADPB1 alleles. However, mismatches have been associated with an increased risk of GvHD and reduction in relapse, consistent with a GvL effect, suggesting that mismatched HLA-DP may represent important antigens in otherwise HLA-matched allo-SCTs $(115,116)$.

However, even in the setting of a fully HLA-matched transplant, immune reactivity against malignant cells provides a major contribution to disease control. Donor T cells recognize host antigens through interactions between their $\mathrm{T}$ cell receptor and peptide bound to a HLA molecule. A particular HLA allele, together with the peptide being presented, form a complex that is recognized by $\mathrm{T}$ cell receptors. T cells play a key role in $\mathrm{GvL}$, even in the HLA-matched setting, which provides evidence that HLApresented peptides are capable of stimulating an anti-leukemic response $(6,117)$.

HLA-presented peptides responsible for eliciting a GvL response are likely to result from mismatched coding germline variants between patient and donor that are expressed in leukemia cells (11). These polymorphic peptides are known as minor histocompatibility antigens (miHAs). Most result from single nucleotide variants (SNVs) but insertions/deletions (indels) can also produce miHAs. In addition to germline variants, somatically acquired genetic variants may result in antigenic peptides, which are known as neoantigens. These are formed from SNVs, indels or chromosomal translocations acquired during leukemogenesis. In order for miHAs or neoantigens to result from germline or somatic genetic variants, they must result in an amino acid change (non-synonymous variants), be expressed in AML cells and presented by HLA molecules. Another category of candidate GvL antigens is leukemia associated antigens, which are derived from proteins overexpressed in leukemic cells that are not expressed in healthy cells (leukemia-associated antigens) (90).

\section{Minor Histocompatibility Antigens}

Compared to neoantigens, there are a large number of mismatched germline variants between patient and donor, which suggests that miHAs might be more important in the GvL response due to the number of potential antigens presented to the donor immune system. From whole exome sequencing of nine patient-donor pairs, an average of 6,445 non-synonymous SNVs were found to be mismatched in an allo-SCT, which provides a large reservoir of potential miHAs (118). Genomewide SNP array data from donors and their stem cell transplant recipients has demonstrated that the average mismatching for coding SNVs is 9.4\% for HLA-identical sibling donors, increasing to $17.3 \%$ for HLA-identical unrelated donors (119). Not all nonsynonymous mismatched variants will produce immunogenic peptides. They must be expressed, processed in the endoplasmic reticulum and bind HLA with high affinity. Approximately 1 in 200 of these non-synonymous SNPs is predicted to be expressed and capable of generating peptides that can be presented by HLA molecules (120). After presentation, in order to generate an immune response, the HLA-peptide complex must bind a $\mathrm{T}$ cell receptor, whose activation is also influenced by the balance of co-stimulatory and co-inhibitory signals.

It is not known whether the number of miHAs triggering a GvL response in a given transplant is very large or whether a small number of antigens play a dominant role. miHAs that have a broad expression across tissues may result in GvHD, whereas hematopoietic-specific miHAs might result in a more restricted GvL response.

In early studies, miHA-specific cytotoxic $\mathrm{T}$ cells were identified from post-transplant samples by demonstrating 
selective cytotoxicity against host but not donor cells (121). In this way, HA- 1 to -5 antigens were described and were found to be recognized by $\mathrm{T}$ cells in a HLA-restricted manner (122). To identify the HLA-A*02:01-restricted HA-2 epitope, HLAbound peptides were eluted by acid treatment and fractionated by reversed-phase high-performance liquid chromatography (HPLC). Individual peptide fractions were tested for their ability to sensitize HLA-A*02:01 cells to lysis by an antigenspecific cytotoxic $\mathrm{T}$ cell clone. Tandem mass spectrometry of the sensitizing peptide fraction was then used to identify the amino acid sequence of the HA-2 antigen, which derived from a class I myosin protein (123).

Once it was appreciated that miHAs occurred as a result of mismatched germline genetic variants, more efficient methods were used to identify miHAs using genetic linkage analysis and genomewide association studies (GWAS) (124). In most studies, miHA phenotypes were defined by assessing reactivity of miHAspecific $\mathrm{T}$ cell clones to EBV-transformed $\mathrm{B}$ cells derived from individual patients (125). Phenotypes were then correlated with SNPs and microsatellite markers throughout the genome, to identify the genetic basis of miHAs (124). This approach was successfully employed to identify the miHAs AAC- 1 and ACC-2 resulting from SNPs in the BCL2A1 gene (126), and LRH-1, from a single base deletion in P2X5 leading to a frameshift (127).

Clinical data correlating individual miHA mismatches with relapse following allo-SCT are limited, as most studies assessing outcomes have focused on GvHD risk rather than anti-tumor effects (124). However, a large cohort study of 849 patients treated with allo-SCT examined 10 previously described autosomal miHAs and correlated patient-donor mismatches with clinical outcomes (128). They found that mismatched miHAs was associated with higher relapse-free survival only in patients with GvHD, but other studies failed to demonstrate this association, perhaps due to small sample sizes (124). A study of three HA-1- and/or HA-2-positive patients with CML or myeloma demonstrated that expansion of miHA-specific $\mathrm{T}$ cells after DLI treatment from their miHA-negative donor coincides with clinical disease responses, suggestive of a GvL effect (129).

Donor/recipient gender mismatching is associated with reduced survival, which supports a role for immune responses against antigens encoded on the $\mathrm{Y}$ chromosome. Stern et al. found that male recipients of female hematopoietic stem cell grafts were more likely to experience severe acute GvHD than those receiving male grafts. In contrast, female recipients of male grafts had increased risk of graft rejection and worse survival than gender-matched recipients, likely as a result of immune reactivity in the host-versus-graft direction against Yencoded proteins (130). Evidence for a GvL effect mediated by reactivity against Y-encoded antigens was provided by a study of 3238 HLA-matched sibling allo-SCT recipients, which found that male recipients of female grafts had a lower risk of relapse of any other sex combination. Female/female and male/male transplants had statistically significant hazard ratios (HR) for relapse of 1.26 and 1.38, respectively, and female recipients of male grafts had a non-significant HR of 1.21 (131). Based on in vitro $\mathrm{T}$ cell activation assays using samples from sex mismatched allo-SCTs, Y-encoded miHAs have been identified from several genes, including DFFRY, JARID1D, DDX3Y, PCDH11Y, and UTY $(132,133)$.

Antibodies against $\mathrm{Y}$ chromosome miHAs in female-to-male gender-mismatched transplants 3 months post-transplant have been shown to predict chronic GvHD (134). This highlights the possibility that B cell responses may be important in GvHD/GvL responses and also demonstrates that antibodies against miHAs could represent biomarkers for these processes.

\section{Neoantigens}

In solid tumors with a high mutational burden, such as melanoma and lung cancer, tumor-specific somatic mutations have been shown to result in large numbers of predicted neoantigens (99). In patients with non-small cell lung cancer, higher numbers of non-synonymous coding mutations were associated with improved response to the programmed cell death-1 (PD-1) inhibitor, pembrolizumab (135). The median number of non-synonymous somatic coding mutations in this lung cancer cohort was 200, most of which are predicted to be non-pathogenic "passenger" mutations. In contrast, AML has amongst the lowest mutation burden of any adult cancer, with an average of 13 mutations in genes and 5 in recurrently mutated genes in AML (136). Therefore, in AML the likelihood of mutations leading to neoantigens is relatively low.

Studies to identify neoantigens have used either whole exome or RNA sequencing data from tumor cells to identify nonsynonymous mutations $(135,137-140)$. Sequencing of a germline sample from the same patient may be used as a control to enable somatically acquired mutations to be distinguished from germline variants. RNA sequencing can be used to filter expressed variants, with the potential to be presented by HLA. Artificial neural networks trained on HLA binding data have been used to predict which variants will bind HLA with high affinity $(141,142)$. Putative HLA class I-binding neoantigens have been tested for their ability to elicit functional $\mathrm{T}$ cell responses using ELISpot assays, intracellular cytokine staining and fluorescent- and barcode-labeled tetramers (143). However, only $4 \%$ of tested peptides elicited a $\mathrm{T}$ cell response (144). This highlights that additional factors beyond HLA binding affinity play an important role in peptide immunogenicity, which likely include protein degradation, peptide processing, and immune tolerance. If mutant and wildtype peptide sequences are similar, immune tolerance to the wildtype sequence is also likely to result in tolerance to the mutant sequence reducing its immunogenicity. This factor is incorporated into a refinement to HLA class I binding predictions, by adding weighting for differences in binding strength between mutant and wildtype peptide sequences (145). Despite the relatively low validation of T cell responses for individual peptides, van Buuren and colleagues were able to detect neoantigen-specific $T$ cell responses in 6 of 8 melanoma patients studied (146). As discussed above, peptides presented by class II are likely to play a key role in eliciting a GvL response against AML $(43,44)$. However, in silico HLAbinding predictions are less robust for class II than class I, which poses a challenge to using this approach to identifying important neoantigens or miHAs. 
Peptide directly bound by MHC on the surface of tumor cells can be assayed by immunoprecipitating the MHC molecules, eluting bound peptides and sequencing them by liquid chromatography-tandem mass spectrometry to identify the amino acid sequence. By integrating this data with genetic variants identified by next-generation sequencing, MHC-presented neoantigens can be identified. Peptidespecific functional $\mathrm{T}$ cell responses can be elicited by a greater proportion of the neoantigens identified using this immunopeptidomic approach than using in silico HLA-binding predictions $(147,148)$.

One proposed method of cancer immune evasion is the loss of mutations associated with neoantigens that trigger a $\mathrm{T}$ cell response. A study of paired non-small cell lung cancer samples taken before immune checkpoint inhibitor therapy and at posttreatment relapse demonstrated that resistant clones had lost neoantigens present pre-treatment (149). A recent study of AML patients similarly predicted neoantigens in diagnostic and relapse samples. However, they failed to find selection against putative neoantigens post-transplant, suggesting that neoantigens are not being targeted by donor-derived $\mathrm{T}$ cells (43). This is likely to be because there is a smaller repertoire of somatic mutations available in AML to generate neoantigens.

Nevertheless, neopeptides resulting from common AML mutations have been shown to elicit $\mathrm{T}$ cell responses in vitro. Greiner and colleagues leveraged the SYFPEITHI database of known HLA-binding peptides to generate mutant NPM1 peptides and tested their ability to activate $\mathrm{T}$ cells from patients and healthy controls using $\mathrm{Cr}^{51}$ release and ELISpot assays for IFN $\gamma$ and granzyme B (150). They identified two immunogenic peptides that activated $\mathrm{CD}^{+} \mathrm{T}$ cells from 33 to $44 \%$ of $\mathrm{AML}$ patients tested. It has similarly been demonstrated that a FLT3 internal tandem duplication (ITD) neopeptide can also induce HLA-restricted autologous CD8 ${ }^{+} \mathrm{T}$ cell responses ex vivo (151).

\section{Leukemia-Associated Antigens}

Leukemia-associated antigens (LAAs) are expressed in leukemia but not in most healthy tissues. Candidate LAAs, such as the cancer-testis family of antigens, may be expressed in immune sanctuary sites such as testes, or in a developmental time-restricted manner (e.g., placenta). Other antigens are not leukemia-specific and are expressed at low levels in normal tissue (e.g., adrenal glands, ovaries, endometrium) but may be overexpressed in leukemia. These antigens include PRAME (preferentially expressed antigen of melanoma), WT1 (Wilms' tumor), hTERT (human telomerase reverse transcriptase), RHAMM (receptor for hyaluronan-mediated motility), G250/CA9 (an LAA derived from carbonic anhydrase), survivin and proteinase- $3(152,153)$. Outside the transplant setting, LAA expression has been found to correlate with improved OS in AML. In a microarray analysis of 116 AML samples, high levels of mRNA for at least one of three LAAs, G250/CA9, PRAME, or RHAMM was associated with significantly improved OS. Specific $\mathrm{T}$ cell responses were demonstrated against LAAs using $\mathrm{Cr}^{51}$ and ELISpot assays in $47-70 \%$ cases, suggesting that the presence of these antigens could potentially enable effective immune surveillance and disease control.
Unlike miHAs and neoantigens, LAAs are proteins that could be expressed by the transplant donor and therefore central $\mathrm{T}$ cell tolerance may prevent these proteins from generating a GvL response.

\section{NK CELLS AND THE GVL EFFECT}

In addition to the established role of T cells in the GvL response, correlative evidence suggests that natural killer (NK) cells may also play a role as effector cells and the relative contributions from $\mathrm{T}$ and NK cells in a given transplant may be influenced by multiple factors, including mode of $\mathrm{T}$ cell depletion, conditioning regimen and post-transplant immunosuppression (154). NK cells are lymphocytes that form part of the innate immune system and are the earliest lymphocytes that recover after hematopoietic stem cell transplantation. Therefore, they are available to exert protective anti-microbial and GvL effects before $\mathrm{T}$ cell reconstitution. Indeed, high levels of donor NK cell chimerism early post-transplant $($ day +14$)$ have been associated with a lower rate of relapse (155).

NK cell effector function is regulated by the balance of signaling from activating and inhibitory surface receptors (156). NK cells were initially functionally characterized by their ability to kill tumor cell lines that lack expression of MHC class I molecules, which led Ljunggren and Karre to propose the "missing self" hypothesis, whereby NK cells kill targets due to the lack of MHC class I presentation of self-peptides (157). This recognition occurs from the interaction between inhibitory killercell immunoglobulin-like receptors (KIRs) on NK cells and MHC class I on target cells. In addition to inhibitory KIR receptors, NK cells express a variety of additional inhibitory (e.g., CD94NKG2A) and activating receptors (e.g., activating KIRs, CD94NKG2C). When an NK cell encounters a target cell, the balance of signals from these receptors determines whether the NK cell will exert a cytotoxic effect.

Downregulation of class I molecules is an important mechanism for evading $\mathrm{T}$ cell immune surveillance that has been described in several tumors $(158,159)$. However, this mechanism can lead to NK cell recognition and activation of cytotoxicity. A counter-mechanism employed by some tumors is upregulation of the non-canonical HLA-E that bind CD94-NKG2 receptors on NK cells and prevent tumor killing (160).

NK cell alloreactivity was demonstrated by Ruggeri et al. (161), who studied 57 transplanted AML patients and showed that KIR ligand incompatibility in the graft-vs.-host direction predicted a reduction in relapse and improved survival. KIR genes are polymorphic and genotypes have been linked to a GvL effect in AML. There are two kinds of haplotype, A and $\mathrm{B}$, which are distinguished by the composition of genes for activating and inhibitory receptors. Type B haplotypes contain more activating genes and correspondingly have been linked to stronger cytotoxic reactions against both virus-infected and malignant cells (45). Significant associations between donors with a type B KIR haplotype and reduced AML relapse post-transplant have been shown, which suggests that a clinically relevant GvL effect might be mediated by NK cells (162). 

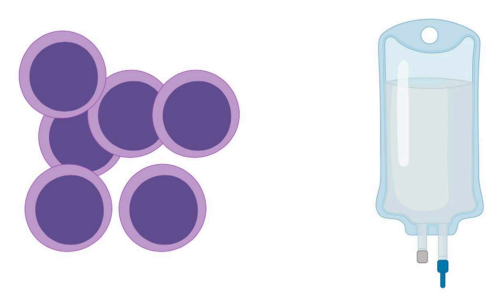

\section{Pre-transplant}

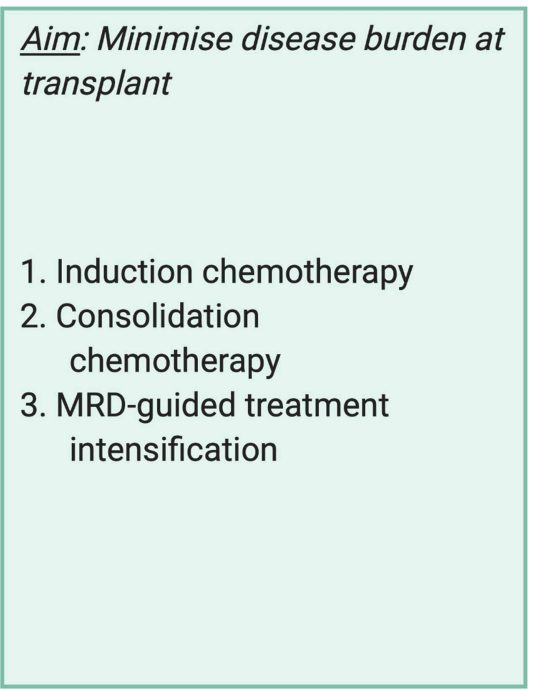

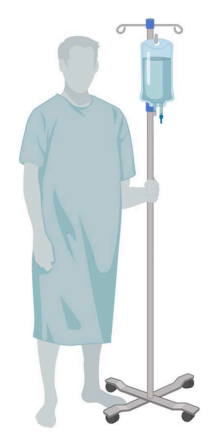

Peri-transplant

Aim: Reduce AML burden,
engraft donor hematopoiesis,
establish GVL effect, minimise
GVHD

1. Conditioning regimen:

- MA or RIC

- T cell depletion ex vivo or in vivo (eg. alemtuzumab, ATG, post-transplant cyclophosphamide)

2. Donor selection (sibling, unrelated, haploidentical, umbilical cord)

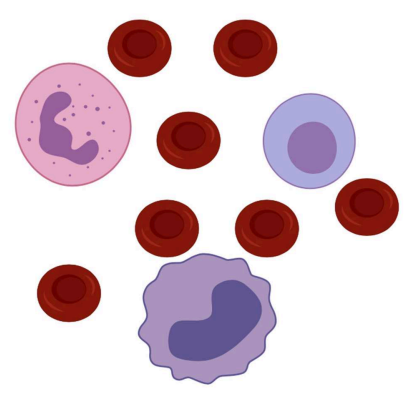

Post-transplant

FIGURE 3 | Methods of improving transplant outcomes in AML. Transplant outcomes for AML patients can be improved by optimizing pre-, peri-, and post-transplant factors for individual patients. MRD-guided treatment and some immunotherapy modalities (peptide vaccination, CAR-T, and bi-specific antibody therapy) are not currently standard practice but are areas of exploration. MRD, minimal residual disease; AML, acute myeloid leukemia; MA, myeloablative conditioning; RIC, reduced intensity conditioning; ATG, anti-thymocyte globulin; GvL, graft-vs.-leukemia; GvHD, graft-vs.-host disease; DLI, donor lymphocyte infusion; CAR-T, chimeric antigen receptor T cell therapy; allo-SCT, allogeneic stem cell transplant. Created with BioRender.com.

\section{IMPROVING TRANSPLANT OUTCOMES IN AML}

To maximize the anti-leukemic effect of allo-SCT, multiple factors must be tailored to the individual patient at different stages of treatment (Figure 3). Positive MRD prior to transplant has consistently been associated with inferior outcomes across multiple studies involving myeloablative and RIC protocols (163) and using sibling, unrelated, and haploidentical donors (164, 165). Therefore, the key aim of pre-transplant treatment is to achieve as deep a remission as possible. As discussed above, there is substantial risk of morbidity and mortality from the toxicity of transplant conditioning and from the immunological effects of GvHD. Therefore, when selecting the conditioning regimen and stem cell donor, these risks are balanced against the reduction in relapse that is achieved from intensive conditioning and a GvL effect.
Identification of GvL antigens is essential to understand in vivo alloimmune anti-leukemic responses. Elucidating key miHAs may enable improved donor selection such that a genetic mismatch between patient and donor can produce a miHA that is predicted to elicit a $\mathrm{T}$ cell response. Whether a mismatch is also likely to result in GvHD may be guided by tissue-specific gene expression data, thus enabling enhancement of $\mathrm{GvL}$ in the absence GvHD. It is not known whether GvL responses in individual patients are driven by a small number of dominant $\mathrm{T}$ cell clones or if a large $\mathrm{T}$ cell repertoire contributes to these responses. Identification of GvL antigens would also enable antigen-specific $\mathrm{T}$ cell responses to be tracked in post-transplant samples, allowing us to better understand the key antigens driving responses in individual patients.

Despite an effective GvL response, AML may relapse posttransplant due to the rapid proliferation overwhelming the protective GvL response. MRD assessment post-transplant may 
predict impending morphological relapse and although not yet established practice, this may enable treatment to be initiated when the disease burden is relatively low and easier to control. This may entail either:

1. Administering post-transplant anti-AML therapy that slows the pace of AML proliferation, to permit an effective donor GvL effect to take hold.

2. Using immunotherapy to enhance the alloreactive effect. This may be targeted to known antigens or employ nonspecific immune activation, such as by DLI or immune checkpoint blockade.

Traditionally, post-transplant AML relapses have been treated with chemotherapy, but response rates to treatment are modest and remissions are usually short-lived. Amongst patients who achieve a complete remission with chemotherapy, consolidation treatment with donor cellular therapy, comprising either DLI or a second allo-SCT in selected patients, significantly improves 2 -year OS (55\% in patients who received cellular therapy vs. $20 \%$ in those who did not) (166). However, many patients who relapse following allo-SCT are unable to tolerate further intensive chemotherapy. Treatment with the hypomethylating agent, azacitidine, is associated with relatively low toxicity and has demonstrated efficacy in this setting. Craddock et al. studied treatment of 181 patients with relapsed AML and MDS posttransplant and found that $25 \%$ responded to azacitidine but concurrent administration of DLI did not improve response rates (167). It has yet to be established whether, in the absence of relapse, post-transplant maintenance chemotherapy has a role in improving outcomes. Treatment with CC-486, an oral formulation of the DNA methyltransferase inhibitor azacytidine, was well tolerated and associated with a 1-year survival of up to $86 \%$ in a single-arm, non-randomized study of AML and MDS patients in post-transplant remission (168). A phase III randomized trial, AMADEUS, is currently evaluating whether maintenance therapy improves relapse-free survival (EudraCT 2018-001012-30) (169). Azacitidine increases the expression of epigenetically silenced antigens and has been shown to result in upregulation of the cancer-testis antigen, MAGE (170). Therefore, in addition to a direct effect on AML cell growth, azacitidine may also enhance the T cell-mediated GvL response.

Our deepening understanding of the molecular landscape of AML in recent years has led to the development of targeted therapies. In relapsed FLT3-ITD AML post-transplant, treatment with the tyrosine kinase inhibitor sorafenib has demonstrated efficacy, both alone and when combined with azacitidine or DLI $(171,172)$. The second-generation tyrosine kinase inhibitors, quizartinib and gilteritinib, exhibit higher specificity for FLT3 and may be more efficacious (173). A randomized phase III trial of single agent quizartinib in relapsed and refractory AML demonstrated higher CR rates (48 vs. $27 \%$ ) and prolonged OS (hazard ratio $0.76,95 \%$ CI $0.58-0.98$ ) compared with salvage chemotherapy. However, although patients who relapsed after allo-SCT were included in the trial, this sub-group was not reported separately (174). An ongoing randomized, placebocontrolled phase II trial is currently assessing gilteritinib maintenance therapy, starting at 30-90 days following allo-SCT and continuing for 24 months (NCT02997202) (175).

Mutations in isocitrate dehydrogenase (IDH) enzymes are found in $5-15 \%$ of patients with AML and inhibitors to both IDH1 (ivosidenib) and IDH2 (enasidenib) mutant enzymes have been approved by the FDA for treatment of relapsed and refractory AML patients. In this group of patients who are challenging to treat, they have achieved complete remission rates of 30.4\% [ivosidenib (176)] and 26.1\% [enasidenib (177)]. Both drugs are currently being assessed as maintenance therapy following allo-SCT in patients with AML harboring the relevant mutations (NCT03564821, NCT03515512) $(178,179)$.

Non-targeted augmentation of post-transplant immune responses using DLI is an established therapy that improves outcomes in some AML patients who relapse post-transplant (92). Another method of non-specific immune activation is using antibodies against immune checkpoint inhibitors, such as PD-1 or CTLA-4. Given their success in treating a range of cancers (180-182), they have also been used in recent studies to treat patients with hematological malignancies following stem cell transplantation. Although these might enhance the GvL response and thereby improve disease control, non-specific immune activation leads to substantial morbidity and mortality from GvHD (183). Concern has also been raised about the possibility of increased risk of venoocclusive disease (VOD) of the liver with immune checkpoint inhibitor therapy. A retrospective study of lymphoma patients treated with PD-1 blockade prior to RIC allo-SCT found an increased rate of severe VOD compared with a retrospective series of RIC transplants (8 vs. 2.1\%) (184). Therefore, it is currently unclear whether immune checkpoint inhibitors will form part of the repertoire of post-transplant therapies for AML.

GvL antigens represent attractive targets for immunotherapy. By selecting a target antigen that is either absent or expressed at a low level in normal tissues, GvHD morbidity can be minimized. One method of producing a targeted GvL response is by peptide vaccination after transplantation, which is predicted to lead to the proliferation of antigen-specific $\mathrm{T}$ cell clones. These $\mathrm{T}$ cells then target leukemia cells that also present the peptide, leading to effective immune control of disease. WT1 is highly expressed highly in many cancers, including most cases of AML (185). A polyvalent vaccine has been used in early phase clinical trials of AML in complete remission outside the transplant setting, with functional $\mathrm{T}$ cell responses demonstrated in vitro by IFN $\gamma$ ELISpot and an increase in WT1 tetramerpositive T cells $(186,187)$. Chapuis et al. targeted WT1 posttransplant using a TCR gene therapy approach. A high affinity WT1 antigen-specific TCR was inserted into donor $\mathrm{CD}^{+} \mathrm{T}$ cells, which were infused prophylactically following allo-SCT into 12 patients. No relapses observed after median followup of 44 months (188). Alternative modes of immunotherapy that direct $\mathrm{T}$ cells against specific antigens could also be employed to enhance the GvL effect, including bi-specific antibodies (189) and chimeric antigen receptor T cell (CAR-T) therapy (190). 


\section{CONCLUSION}

To achieve a cure, most patients with AML require an alloSCT. Although this is an effective therapy, $32 \%$ of patients will relapse and these cases are associated with poor outcomes (166). This highlights the need to improve treatments to reduce relapse whilst avoiding non-relapse mortality, which is largely due to GvHD and infection. It has been almost 40 years since the GvL effect was first identified in retrospective, correlative clinical studies and although it is clear that $\mathrm{T}$ cells play a crucial role, it is not known which AML antigens trigger and sustain a protective GvL donor T cell response in the HLAmatched setting (27). It is probable that GvL responses result from the genetic disparity between patient and donor and given the correlation between GvHD and GvL, these processes are likely to have shared mechanisms. De-coupling the processes that drive GvL responses from those that cause GvHD represents a key challenge in transplantation, that might allow us to harness protective anti-tumor responses, whilst avoiding toxicity to normal tissues.

\section{REFERENCES}

1. Passweg JR, Baldomero H, Bader P, Bonini C, Cesaro S, Dreger P, et al. Hematopoietic stem cell transplantation in Europe 2014: more than 40 000 transplants annually. Bone Marrow Transplant. (2016) 51:786-92. doi: 10.1038/bmt.2016.20

2. Bower H, Andersson TML, Bjorkholm M, Dickman PW, Lambert PC, Derolf AR. Continued improvement in survival of acute myeloid leukemia patients: an application of the loss in expectation of life. Blood Cancer J. (2016) 6:e390. doi: 10.1038/bcj.2016.3

3. Burnett A, Wetzler M, Löwenberg B. Therapeutic advances in acute myeloid leukemia. J Clin Oncol. (2011) 29:487-94. doi: 10.1200/JCO.2010.30.1820

4. Goyal G, Gundabolu K, Vallabhajosyula S, Silberstein PT, Bhatt VR. Reduced-intensity conditioning allogeneic hematopoietic cell transplantation for older adults with acute myeloid leukemia. Cancer Control. (2016) 18:237-45. doi: 10.1177/107327481101800404

5. Vyas P, Appelbaum FR, Craddock C. Allogeneic hematopoietic cell transplantation for acute myeloid leukemia. Biol Blood Marrow Transplant. (2015) 21:8-15. doi: 10.1016/j.bbmt.2014.10.026

6. Zilberberg J, Feinman R, Korngold R. Strategies for the identification of $\mathrm{T}$ cell-recognized tumor antigens in hematological malignancies for improved graft-versus-tumor responses after allogeneic blood and marrow transplantation. Biol Blood Marrow Transplant. (2015) 21:1000-7. doi: 10.1016/j.bbmt.2014.11.001

7. Ferrara JLM, Levine JE, Reddy P, Holler E. Graft-versus-host disease. Lancet. (2009) 373:1550-61. doi: 10.1016/S0140-6736(09)60237-3

8. Rowe JM. Graft-versus-disease effect following allogeneic transplantation for acute leukaemia. Best Pract Res Clin Haematol. (2008) 21:485-502. doi: 10.1016/j.beha.2008.07.002

9. Hobbs G, Perales M-A. Effects of T-cell depletion on allogeneic hematopoietic stem cell transplantation outcomes in AML patients. J Clin Med. (2015) 4:488-503. doi: 10.3390/jcm4030488

10. Kolb HJ. Graft-versus-leukemia effects of transplantation and donor lymphocytes. Blood. (2008) 112:4371-83. doi: 10.1182/blood-2008-03-077974

11. Griffioen M, Van Bergen CAM, Falkenburg JHF. Autosomal minor histocompatibility antigens: how genetic variants create diversity in immune targets. Front Immunol. (2016) 7:100. doi: 10.3389/fimmu.2016.00100

12. Center for International Blood and Marrow Transplant, a contractor for the C.W. Bill Young Cell Transplantation Program operated through the U. S.

\section{AUTHOR CONTRIBUTIONS}

CS wrote the first draft of the manuscript. Both CS and PV reviewed and edited the final version.

\section{FUNDING}

CS was funded by the Wellcome Trust (Grant reference: 211023/Z/18/Z). PV acknowledges funding from the MRC Disease Team Awards (G1000729/94931 and MR/L008963/1), MRC Molecular Haematology Unit (MC_UU_12009/11), and the Oxford Partnership Comprehensive Biomedical Research Centre (NIHR BRC Funding scheme. oxfbrc-2012-1), Bloodwise and Children with Leukaemia Specialist Programme Grant 13001, NIHR Oxford Biomedical Research Fund.

\section{ACKNOWLEDGMENTS}

The authors wish to thank Prof. Ronjon Chakraverty (University College London) for critical review of the manuscript and advice.

Department of Health and Human Services, Health Resources and Services Administration, Healthcare Systems Bureau. U.S. Transplant Data by Disease Report, AML - Acute myelogenous leukemia, Patient Survival 2011 - 2015. U.S. Transplant Data by Disease Report (2019).

13. Barnes DWH, Corp MJ, Loutit JF, Neal FE. Treatment of murine leukaemia with X Rays and homologous bone marrow. Br Med J. (1956) 2:626-7. doi: 10.1136/bmj.2.4993.626

14. Thomas ED, Lochte HL, Lu WC, Ferrebee JW. Intravenous infusion of bone marrow in patients receiving radiation and chemotherapy. $N$ Engl J Med. (1957) 257:491-6. doi: 10.1056/NEJM195709122571102

15. Henig I, Zuckerman T. Hematopoietic stem cell transplantation-50 years of evolution and future perspectives. Rambam Maimonides Med J. (2014) 5:e0028. doi: 10.5041/RMMJ.10162

16. Borghans JAM, Beltman JB, De Boer RJ. MHC polymorphism under host-pathogen coevolution. Immunogenetics. (2004) 55:732-9. doi: 10.1007/s00251-003-0630-5

17. Dausset PJ. Iso-leuco-anticorps. Acta haemat. (1958) 166:156-66. doi: 10.1159/000205478

18. Thorsby E. A short history of HLA. Tissue Antigens. (2009) 74:101-16. doi: $10.1111 / \mathrm{j} .1399-0039.2009$. 01291.x

19. van Rood JJ, Eernisse JG, va Leeuwen A. Leucocyte antibodies in sera from pregnant women. VoxSanguinis. (1958) 12:1735-6. doi: 10.1038/1811735a0

20. Payne R, Tripp M, Weigle J, Bodmer W, Bodmer J. A new leukocyte isoantigen system in man. Cold Spring Harb Symp Quant Biol. (1964) 29:285-95. doi: 10.1101/SQB.1964.029.01.031

21. Mathe G, Amiel JL, Schwarzenberg A, Cattan M, Schneider M, De Fries MJ. Successful allogenic bone marrow transplantation in man: chimerism, induced specific tolerance and possible anti-leukemic effects. Blood. (1965) 25:179-96. doi: 10.1182/blood.V25.2.179.179

22. Matsukura M, Mery AM, Amiel JL, Mathe G. Investigation on a test of histocompatibility for allogeneic grafts. Transplantation. (1962) 1:61-4. doi: 10.1097/00007890-196301010-00007

23. Thomas DE, Buckner D, Banaji M, Clift RA, Fefer E, Flournoy N, et al. One hundred patients with acute leukemia treated by chemotherapy, total body irradiation, and allogeneic marrow transplantation. Blood. (1977) 49:511-33. doi: 10.1182/blood.V49.4.511.511

24. Thomas ED, Buckner CD, Clift RA, Fefer A, Johnson L, Neiman PE, et al. Marrow transplantation for nonlymphoblastic leukemia in first remission. $N$ Engl J Med. (1979) 301:597-99. doi: 10.1056/NEJM197909133011109 
25. Weiden PL, Sullivan KM, Flournoy N, Storb R, Thomas ED. Antileukemic effect of chronic graft-versus-host disease. N Engl J Med. (1981) 304:1529-33. doi: 10.1056/NEJM198106183042507

26. Hansen JA, Clift RA, Thomas ED, Buckner CD, Storb R, Giblett ER. Transplantation of marrow from an unrelated donor to a patient with acute leukemia. $N$ Engl J Med. (1980) 303:565-7. doi: 10.1056/NEJM198009043031007

27. Singh AK, McGuirk JP. Allogeneic stem cell transplantation: a historical and scientific overview. Cancer Res. (2016) 76:6445-51. doi: 10.1158/0008-5472.CAN-16-1311

28. World Marrow Donor Association (WMDA). Total Number of Donors and Cord Blood Units. (2019). Available online at: https://statistics.wmda.info (accessed June 25, 2019).

29. Gragert L, Eapen M, Williams E, Freeman J, Spellman S, Baitty R, et al. HLA match likelihoods for hematopoietic stem-cell grafts in the U.S. registry. $N$ Engl J Med. (2014) 371:339-48. doi: 10.1056/NEJMsa1311707

30. Yang B, Yu R, Cai L, Guo B, Chen H, Zhang H, et al. Haploidentical versus matched donor stem cell transplantation for patients with hematological malignancies: a systemic review and meta-analysis. Bone Marrow Transplant. (2019) 54:99-122. doi: 10.1038/s41409-018-0239-9

31. Aversa F, Terenzi A, Tabilio A, Falzetti F, Carotti A, Ballanti S, et al. Full haplotype-mismatched hematopoietic stem-cell transplantation: a phase II study in patients with acute leukemia at high risk of relapse. J Clin Oncol. (2005) 23:3447-54. doi: 10.1200/JCO.2005.09.117

32. Fuchs EJ. Haploidentical transplantation for hematologic malignancies: where do we stand? Hematol Am Soc Hematol Educ Prog. (2012) 2012:230-6. doi: 10.1182/asheducation.V2012.1.230.3798312

33. Duarte RF, Labopin M, Bader P, Basak GW, Bonini C, Chabannon $\mathrm{C}$, et al. Indications for haematopoietic stem cell transplantation for haematological diseases, solid tumours and immune disorders: current practice in Europe, 2019. Bone Marrow Transplant. (2019) 54:1525-52. doi: 10.1038/s41409-019-0516-2

34. Sorror ML, Maris MB, Storb R, Baron F, Sandmaier BM, Maloney DG, et al. Hematopoietic cell transplantation (HCT)- specific comorbidity index : a new tool for risk assessment before allogeneic HCT. Blood. (2005) 106:2912-20. doi: 10.1182/blood-2005-05-2004

35. Cornelissen JJ, Gratwohl A, Schlenk RF, Sierra J, Bornhauser M, Juliusson $\mathrm{G}$, et al. The European LeukemiaNet AML Working Party consensus statment on allogenic HSCT for patients with AML in remission: an integrated-risk adapted approach. Nat Publ Gr. (2012) 9:579-90. doi: 10.1038/nrclinonc.2012.150

36. Papaemmanuil E, Gerstung M, Bullinger L, Gaidzik VI, Paschka P, Roberts ND, et al. Genomic classification and prognosis in acute myeloid leukemia. N Engl J Med. (2016) 374:2209-21. doi: 10.1056/NEJMoa1516192

37. Dohner H, Estey E, Grimwade D, Amadori S, Appelbaum FR, Buchner $\mathrm{T}$, et al. Diagnosis and management of AML in adults: 2017 ELN recommendations from an international expert panel. Blood. (2017) 129:424-48. doi: 10.1182/blood-2016-08-733196

38. Short NJ, Ravandi F. How close are we to incorporating measurable residual disease into clinical practice for acute myeloid leukemia? Haematologica. (2019) 104:1532-41. doi: 10.3324/haematol.2018.208454

39. Ravandi F, Walter RB, Freeman SD. Evaluating measurable residual disease in acute myeloid leukemia. Blood Adv. (2018) 2:1356-66. doi: 10.1182/bloodadvances.2018016378

40. Jongen-Lavrencic M, Grob T, Hanekamp D, Kavelaars FG, al Hinai A, Zeilemaker A, et al. Molecular minimal residual disease in acute myeloid leukemia. N Engl J Med. (2018) 378:1189-99. doi: 10.1056/NEJMoa1716863

41. Breems DE, Van Putten WLJ, Huijgens PC, Ossenkoppele GJ, Verhoef GEG, Verdonck LF, et al. Prognostic index for adult patients with acute myeloid leukemia in first relapse. J Clin Oncol. (2005) 23:1969-78. doi: 10.1200/JCO.2005.06.027

42. Seliger B, Kloor M, Ferrone S. HLA class II antigen-processing pathway in tumors: molecular defects and clinical relevance. Oncoimmunology. (2017) 6:1-10. doi: 10.1080/2162402X.2016.1171447

43. Christopher MJ, Petti AA, Rettig MP, Miller CA, Chendamarai E, Duncavage EJ, et al. Immune escape of relapsed AML cells after allogeneic transplantation. N Engl J Med. (2018) 379:2330-41. doi: 10.1056/NEJMoa1808777
44. Toffalori C, Zito L, Gambacorta V, Riba M, Oliveira G, Bucci G, et al. Immune signature drives leukemia escape and relapse after hematopoietic cell transplantation. Nat Med. (2019) 25:603-11. doi: 10.1038/s41591-019-0400-z

45. Warren EH, Deeg HJ. Dissecting graft-versus-leukemia from graft-versushost disease using novel strategies. Tissue Antigens. (2013) 81:183-93. doi: $10.1111 / \tan .12090$

46. Horowitz M, Gale RP, Sondel PM, Goldman JM, Kersey J, Kolb H-J, et al. Graft-versus-leukemia reactions after bone marrow transplantation. Proc Am Math Soc. (1990) 75:555-62. doi: 10.1182/blood.V75.3.555.bloodjournal753555

47. Valcárcel D, Martino R, Caballero D, Martin J, Ferra C, Nieto JB, et al. Sustained remissions of high-risk acute myeloid leukemia and myelodysplastic syndrome after reduced-intensity conditioning allogeneic hematopoietic transplantation: chronic graft-versus-host disease is the strongest factor improving survival. J Clin Oncol. (2008) 26:577-84. doi: 10.1200/JCO.2007.11.1641

48. Baron F, Labopin M, Niederwieser D, Vigouroux S, Cornelissen JJ, Malm C, et al. Impact of graft-versus-host disease after reduced-intensity conditioning allogeneic stem cell transplantation for acute myeloid leukemia: a report from the Acute Leukemia Working Party of the European group for blood and marrow transplantation. Leukemia. (2012) 26:2462-8. doi: 10.1038/leu.2012.135

49. Kato M, Kurata M, Kanda J, Kato K, Tomizawa D, Kudo K, et al. Impact of graft-versus-host disease on relapse and survival after allogeneic stem cell transplantation for pediatric leukemia. Bone Marrow Transplant. (2019) 54:68-75. doi: 10.1038/s41409-018-0221-6

50. Stern M, de Wreede LC, Brand R, van Biezen A, Dreger P, Mohty $M$, et al. Sensitivity of hematological malignancies to graft-versushost effects: an EBMT megafile analysis. Leukemia. (2014) 28:2235-40. doi: 10.1038/leu.2014.145

51. Woolfrey A, Lee SJ, Gooley TA, Malkki M, Martin PJ, Pagel JM, et al. HLAallele matched unrelated donors compared to HLA-matched sibling donors: role of cell source and disease risk category. Biol Blood Marrow Transplant. (2010) 16:1382-7. doi: 10.1016/j.bbmt.2010.03.024

52. Ringden O, Pavletic SZ, Anasetti C, Barrett J, Wang T, Wang D, et al. The graft-versus-leukemia effect using matched unrelated donors is not superior to HLA-identical siblings for hematopoietic stem cell transplantation. Blood. (2009) 113:3110-8. doi: 10.1182/blood-2008-07-163212

53. Schlenk RF, Döhner K, Mack S, Stoppel M, Kiraly F, Gotze K, et al. Prospective evaluation of allogeneic hematopoietic stem-cell transplantation from matched related and matched unrelated donors in younger adults with high-risk acute myeloid leukemia: German-Austrian trial AMLHD98A. J Clin Oncol. (2010) 28:4642-8. doi: 10.1200/JCO.2010.28.6856

54. Brissot E, Labopin M, Stelljes M, Ehninger G, Schwerdtfeger R, Finke J, et al. Comparison of matched sibling donors versus unrelated donors in allogeneic stem cell transplantation for primary refractory acute myeloid leukemia: a study on behalf of the Acute Leukemia Working Party of the EBMT. $J$ Hematol Oncol. (2017) 10:1-10. doi: 10.1186/s13045-017-0498-8

55. Lee SJ, Klein J, Haagenson M, Baxter-Lowe LA, Confer D, Eapen M, et al. High-resolution donor-recipient HLA matching contributes to the success of unrelated donor marrow transplantation. Blood. (2007) 110:4576-84. doi: 10.1182/blood-2007-06-097386

56. Saber W, Opie S, Rizzo JD, Zhang M-J, Horowitz MM, Schriber J. Outcomes after matched unrelated donor versus identical sibling hematopoietic cell transplantation in adults with acute myelogenous leukemia. Blood. (2012) 119:3908-16. doi: 10.1182/blood-2011-09-381699

57. Bensinger WI. Allogeneic transplantation: peripheral blood vs. bone marrow. Curr Opin Oncol. (2012) 24:191-6. doi: 10.1097/CCO.0b013e32834f5c27

58. Bensinger WI, Martin PJ, Storer B, Clift RA, Forman SJ, Negrin R, et al. Transplantation of bone marrow as compared with peripheral-blood cells from HLA-identical relatives in patients with hematologic cancers. $N$ Engl J Med. (2001) 344:175-81. doi: 10.1056/NEJM200101183440303

59. Couban S, Simpson DR, Barnett MJ, Bredeson C, Hubesch L, Howson-Jan K, et al. A randomized multicenter comparison of bone marrow and peripheral blood in recipients of matched sibling allogeneic transplants for myeloid malignancies. Blood. (2002) 100:1525-31. doi: 10.1182/blood-2002-01-0048 
60. Blaise D, Kuentz M, Fortanier C, Bourhis JH, Milpied N, Sutton L, et al. Randomized trial of bone marrow versus lenograstim-primed blood cell allogeneic transplantation in patients with early-stage leukemia: a report from the société française de greffe de moelle. J Clin Oncol. (2000) 18:537. doi: 10.1200/JCO.2000.18.3.537

61. Heldal D, Brinch Y, Floisand Y, Dybedal I, Gedde-Dahl T, Holme PA, et al. Long-term ( $>5$ years) follow-up of a randomized study of allogeneic stem cell transplantation with stem cells from blood or bone marrow. Bone Marrow Transplant. (2000) 25:1129-36. doi: 10.1038/sj.bmt.1702422

62. Gratwohl A, Brand R, Frassoni F, Rocha V, Niederwieser D, Reusser P, et al. Cause of death after allogeneic haematopoietic stem cell transplantation (HSCT) in early leukaemias: an EBMT analysis of lethal infectious complications and changes over calendar time. Bone Marrow Transplant. (2005) 36:757-69. doi: 10.1038/sj.bmt.1705140

63. van Dicke KA, Hooft JI, van Bekkum DW. The selective elimination of immunologically competent cells from bone marrow and lymphatic cell mixtures. II. Mouse spleen cell fractionation on a discontinuous albumin gradient. Transplantation. (1968) 6:562-70. doi: 10.1097/00007890-196807000-00009

64. Ho VT, Soiffer RJ. The history and future of T-cell depletion as graftversus-host disease prophylaxis for allogeneic hematopoietic stem cell transplantation. Blood. (2001) 98:3192-204. doi: 10.1182/blood.V98.12.3192

65. Waldmann H, Hale G, Cividalli G, Weshler Z, Manor D, Rachmilewitz EA, et al. Elimination of graft-versus-host disease by in-vitro depletion of alloreactive lymphocytes with a monoclonal rat antihuman lymphocyte antibody (campath-1). Lancet. (1984) 324:483-6. doi: 10.1016/S0140-6736(84)92564-9

66. Heit W, Bunjes D, Wiesneth M, Schmeiser T, Arnold R, Hale G, et al. Ex vivo T-cell depletion with the monoclonal antibody Campath-1 plus human complement effectively prevents acute graft-versus-host disease in allogeneic bone marrow transplantation. Br J Haematol. (1986) 64:479-86. doi: 10.1111/j.1365-2141.1986.tb02203.x

67. Apperley J, Jones L, Hale G, Waldmann H, Hows J, Rombos Y, et al. Bone marrow transplantation for patients with chronic myeloid leukaemia: Tcell depletion with Campath-1 reduces the incidence of graft-versus-host disease but may increase the risk of leukaemic relapse. Bone Marrow Transpl. (1986) 1:53-66.

68. Marmont AM, Horowitz MM, Gale RP, Sobocinski K, Ash RC, van Bekkum DW, et al. T-Cell depletion of HLA-identical transplants in leukemia. Blood. (1991) 78:2120-30. doi: 10.1182/blood.V78.8.2120.2120

69. Kernan NA, Bordignon C, Heller G, Cunningham I, Castro-Malaspina H, Shank B, et al. Graft failure after T-cell-depleted human leukocyte antigen identical marrow transplants for leukemia: I. Analysis of risk factors and results of secondary transplants. Blood. (2017) 74:2227-36. doi: 10.1182/blood.V74.6.2227.bloodjournal7462227

70. Saad A, Lamb LS. Ex vivo T-cell depletion in allogeneic hematopoietic stem cell transplant: past, present and future. Bone Marrow Transplant. (2017) 52:1241-8. doi: 10.1038/bmt.2017.22

71. Pasquini MC, Devine S, Mendizabal A, Baden LR, Wingard JR, Lazarus $\mathrm{HM}$, et al. Comparative outcomes of donor graft CD34+ selection and immune suppressive therapy as graft-versus-host disease prophylaxis for patients with acute myeloid leukemia in complete remission undergoing HLA-matched sibling allogeneic hematopoietic cell transpl. J Clin Oncol. (2012) 30:3194-201. doi: 10.1200/JCO.2012.41.7071

72. Ho VT, Kim HT, Li S, Hochberg EP, Cutler C, Lee SJ, et al. Partial CD8+ T-cell depletion of allogeneic peripheral blood stem cell transplantation is insufficient to prevent graft-versus-host disease. Bone Marrow Transplant. (2004) 34:987-94. doi: 10.1038/sj.bmt.1704690

73. Federmann B, Bornhauser M, Meisner C, Kordelas L, Beelen DW, Stuhler G, et al. CD3/CD19 depletion and reduced intensity conditioning: a phase II study. Haematologica. (2012) 97:1523-31. doi: 10.3324/haematol.2011.059378

74. Drobyski WR, Majewski D, Hanson G. Graft-facilitating doses of ex vivo activated $\gamma \delta \mathrm{T}$ cells do not cause lethal murine graftvs.-host disease. Biol Blood Marrow Transplant. (1999) 5:222-30. doi: 10.1053/bbmt.1999.v5.pm10465102

75. Mehta J, Singhal S, Gee AP, Chiang K-Y, Godder K, van Rhee F, et al. Bone marrow transplantation from partially HLA-mismatched family donors for acute leukemia: single-center experience of 201 patients. Bone Marrow Transplant. (2004) 33:389-96. doi: 10.1038/sj.bmt.1704391

76. Lamb LS, Gee AP, Hazlett LJ, Musk P, Parrish RS, O'Hanlon TP, et al. Influence of $\mathrm{T}$ cell depletion method on circulating $\gamma \delta \mathrm{T}$ cell reconstitution and potential role in the graft-versus-leukemia effect. Cytotherapy. (1999) 1:7-19. doi: 10.1080/0032472031000141295

77. Meeh PF, King M, O’Brien RL, Muga S, Buckhalts P, Neuberg R, et al. Characterization of the $\gamma \delta \mathrm{T}$ cell response to acute leukemia. Cancer Immunol Immunother. (2006) 55:1072-80. doi: 10.1007/s00262-005-0094-6

78. Beck BH, Kim HG, Kim H, Samuel S, Liu Z, Shrestha R, et al. Adoptively transferred ex vivo expanded $\gamma \delta$-T cells mediate in vivo antitumor activity in preclinical mouse models of breast cancer. Breast Cancer Res Treat. (2010) 122:135-44. doi: 10.1007/s10549-009-0527-6

79. Chakraverty R, Orti G, Roughton M, Shen J, Fielding A, Kottaridis P, et al. Impact of in vivo alemtuzumab dose before reduced intensity conditioning and HLA-identical sibling stem cell transplantation: pharmacokinetics, GVHD, and immune reconstitution. Blood. (2010) 116:3080-8. doi: 10.1182/blood-2010-05-286856

80. Bacigalupo A, Lamparelli T, Bruzzi P, Guidi S, Alessandrino PE, di Bartolomeo P, et al. Antithymocyte globulin for graft-versus-host disease prophylaxis in transplants from unrelated donors : 2 randomized studies from Gruppo Italiano Trapianti Midollo Osseo (GITMO). Blood. (2001) 98:2942-7. doi: 10.1182/blood.V98.10.2942

81. Luznik L, O’Donnell P V., Symons HJ, Chen AR, Lefell MS, Zahurak M, et al. HLA-haploidentical bone marrow transplantation for hematologic malignancies using nonmyeloablative conditioning and high-dose, posttransplantation cyclophosphamide. Biol Blood Marrow Transplant. (2008) 14:641-50. doi: 10.1016/j.bbmt.2008.03.005

82. Ali R, Ramdial J, Algaze S, Beitinjaneh A. The role of anti-thymocyte globulin or alemtuzumab-based serotherapy in the prophylaxis and management of graft-versus-host disease. Biomedicines. (2017) 5:67. doi: 10.3390/biomedicines5040067

83. Malladi RK, Peniket AJ, Littlewood TJ, Towlson KE, Pearce R, Yin $\mathrm{J}$, et al. Alemtuzumab markedly reduces chronic GVHD without affecting overall survival in reduced-intensity conditioning sibling alloSCT for adults with AML. Bone Marrow Transplant. (2009) 43:709-15. doi: 10.1038/bmt.2008.375

84. Schmidt-Hieber M, Schwarck S, Stroux A, Ganepola S, Reinke P, Thiel E, et al. Immune reconstitution and cytomegalovirus infection after allogeneic stem cell transplantation: the important impact of in vivo $\mathrm{T}$ cell depletion. Int J Hematol. (2010) 91:877-85. doi: 10.1007/s12185-010-0597-6

85. Ciurea SO, Mulanovich V, Saliba RM, Bayraktar UD, Jiang Y, Bassett R, et al. Improved early outcomes using a $\mathrm{T}$ cell replete graft compared with $\mathrm{T}$ cell depleted haploidentical hematopoietic stem cell transplantation. Biol Blood Marrow Transplant. (2012) 18:1835-44. doi: 10.1016/j.bbmt.2012.07.003

86. Namdaroglu S, Kaya AH, Batgi H, Kayikci O, Dal MS, Iskender D, et al. Impacts of post-transplantation cyclophosphamide treatment after allogeneic hematopoietic stem cell transplantation in acute myeloid leukemia. Sci Rep. (2019) 9:1-6. doi: 10.1038/s41598-019-38644-1

87. Sullivan KM, Storb R, Buckner CD, Fefer A, Fisher L, Weiden PL, et al. Graft-versus-host disease as adoptive immunotherapy in patients with advanced hematologic neoplasms. N Engl J Med. (1989) 320:828-34. doi: 10.1056/NEJM198903303201303

88. Kolb HJ, Mittermuller J, Clemm C, Holler E, Ledderose G, Brehm G, et al. Donor leukocyte transfusions for treatment of recurrent chronic myelogenous leukemia in marrow transplant patients. Blood. (1990) 76:2462-5. doi: 10.1182/blood.V76.12.2462.2462

89. Dazzi F, Szydlo RM, Cross NC, Craddock C, Kaeda J, Kanfer E, et al. Durability of responses following donor lymphocyte infusions for patients who relapse after allogeneic stem cell transplantation for chronic myeloid leukemia. Blood. (2000) 96:2712-6. doi: 10.1182/blood.V95.1.67

90. Dickinson AM, Norden J, Li S, Hromadnikova I, Schmid C, Schmetzer $\mathrm{H}$, et al. Graft-versus-leukemia effect following hematopoietic stem cell transplantation for leukemia. Front Immunol. (2017) 8:496. doi: 10.3389/fimmu.2017.00496

91. Orti G, Barba P, Fox L, Salamero O, Bosch F, Valcarcel D. Donor lymphocyte infusions in AML and MDS: enhancing the graft-versus-leukemia effect. Exp Hematol. (2017) 48:1-11. doi: 10.1016/j.exphem.2016.12.004 
92. Schmid C, Labopin M, Nagler A, Bornhauser M, Finke J, Fassas A, et al. Donor lymphocyte infusion in the treatment of first hematological relapse after allogeneic stem-cell transplantation in adults with acute myeloid leukemia: a retrospective risk factors analysis and comparison with other strategies by the EBMT acute leukem. J Clin Oncol. (2007) 25:4938-45. doi: 10.1200/JCO.2007.11.6053

93. Schmid C, Schleuning M, Ledderose G, Tischer J, Kolb HJ. Sequential regimen of chemotherapy, reduced-intensity conditioning for allogeneic stem-cell transplantation, and prophylactic donor lymphocyte transfusion in high-risk acute myeloid leukemia and myelodysplastic syndrome. J Clin Oncol. (2005) 23:5675-87. doi: 10.1200/JCO.2005.07.061

94. Jedlickova Z, Schmid C, Koenecke C, Hertenstein B, Baurmann H, Schwerdtfeger $\mathrm{R}$, et al. Long-term results of adjuvant donor lymphocyte transfusion in AML after allogeneic stem cell transplantation. Bone Marrow Transplant. (2016) 51:663-7. doi: 10.1038/bmt.2015.234

95. Prophylactic and Pre-Emptive DLI for Myeloid Malignancies (PRO-DLI). Available online at: https://www.hra.nhs.uk/planning-and-improvingresearch/application-summaries/research-summaries/prophylatic-andpre-emptive-dli-for-myeloid-malignancies-pro-dli/ (accessed June 28, 2019).

96. Bacigalupo A, Ballen K, Rizzo D, Giralt S, Lazarus H, Ho V, et al. Defining the intensity of conditioning regimens: working definitions. Biol Blood Marrow Transplant. (2009) 15:1628-33. doi: 10.1016/j.bbmt.2009.07.004

97. McClune BL, Weisdorf DJ, Pedersen TL, da Silva GT, Tallman MS, Sierra J, et al. Effect of age on outcome of reduced-intensity hematopoietic cell transplantation for older patients with acute myeloid leukemia in first complete remission or with myelodysplastic syndrome. J Clin Oncol. (2010) 28:1878-87. doi: 10.1200/JCO.2009.25.4821

98. Weisdorf DJ. Reduced-intensity versus myeloablative allogeneic transplantation. Hematol Oncol Stem Cell Ther. (2017) 10:321-6. doi: 10.1016/j.hemonc.2017.05.002

99. Schumacher TN, Schreiber RD. Realising the promise: neoantigens in cancer immunotherapy. Science. (2015) 348:69-74. doi: 10.1126/science.aaa4971

100. Vago L, Perna SK, Zanussi M, Mazzi B, Barlassina C, Stanghellini MTL, et al. Loss of mismatched HLA in leukemia after stem-cell transplantation. N Engl J Med. (2009) 361:478-88. doi: 10.1056/NEJMoa0811036

101. Toffalori C. To the editor: Genomic loss of patient-specific HLA in acute myeloid leukemia relapse after well-matched. Blood. (2012) 119:4813-5. doi: 10.1182/blood-2012-02-411686

102. Jan M, Leventhal MJ, Morgan EA, Wengrod JC, Nag A, Drinan SD, et al. Recurrent genetic HLA loss in AML relapsed after matched unrelated allogeneic hematopoietic cell transplantation. Blood Adv. (2019) 3:2199-204. doi: 10.1182/bloodadvances.2019000445

103. Ahmadzadeh M, Johnson LA, Heemskerk B, Wunderlich JR, Dudley ME, White DE, et al. Tumor antigen - specific CD8 T cells infiltrating the tumor express high levels of PD-1 and are functionally impaired Tumor antigen - specific CD8 T cells infiltrating the tumor express high levels of PD-1 and are functionally impaired. Blood. (2009) 114:1537-44. doi: 10.1182/blood-2008-12-195792

104. Puram SV, Tirosh I, Parikh AS, Patel AP, Yizhak K, Gillespie S, et al. Single-cell transcriptomic analysis of primary and metastatic tumor ecosystems in head and neck cancer. Cell. (2017) 171:1611-24.e24. doi: 10.1016/j.cell.2017.10.044

105. Norde WJ, Maas F, Hobo W, Korman A, Quigley M, Kester MGD, et al. PD1/PD-L1 interactions contribute to functional T-cell impairment in patients who relapse with cancer after allogeneic stem cell transplantation. Cancer Res. (2011) 71:5111-22. doi: 10.1158/0008-5472.CAN-11-0108

106. Mussai F, De Santo C, Abu-dayyeh I, Booth S, Quek L, McEwen-Smith $\mathrm{RM}$, et al. Acute myeloid leukemia creates an arginase-dependent immunosuppressive microenvironment. Blood. (2019) 122:749-59. doi: 10.1182/blood-2013-01-480129

107. Folgiero V, Goffredo BM, Filippini P, Masetti R, Bonanno G, Caruso R, et al. Indoleamine 2,3-dioxygenase 1 (IDO1) activity in leukemia blasts correlates with poor outcome in childhood acute myeloid leukemia. Oncotarget. (2013) 5:2052-64. doi: 10.18632/oncotarget.1504

108. Zeiser R, Vago L. Mechanisms of immune escape after allogeneic hematopoietic cell transplantation. Blood. (2019) 133:1290-7. doi: 10.1182/blood-2018-10-846824
109. Park HH, Kim M, Lee B, Lim J, Kim Y, Lee EJ, et al. Intracellular IL-4 IL10 , and IFN-g levels of leukemic cells and bone marrow T cells in acute leukemia. Ann Clin Lab Sci. (2006) 36:7-15.

110. Dilillo DJ, Weinberg JB, Yoshizaki A, Horikawa M, Bryant JM, Iwata Y, et al. Chronic lymphocytic leukemia and regulatory B cells share IL-10competence and immunosuppressive function. Leukemia. (2013) 27:170-82. doi: 10.1038/leu.2012.165

111. Colpitts SL, Stonier SW, Stoklasek TA, Root SH, Aguila HL, Schluns KS, et al. Transcriptional regulation of IL-15 expression during hematopoiesis. J Immunol. (2013) 191:3017-24. doi: 10.4049/jimmunol.1301389

112. Thiant S, Yakoub-Agha I, Magro L, Trauet J, Coiteux V, Jouet J-P, et al. Plasma levels of IL-7 and IL-15 in the first month after myeloablative BMT are predictive biomarkers of both acute GVHD and relapse. Bone Marrow Transplant. (2010) 45:1546-52. doi: 10.1038/bmt.2010.13

113. Mathew NR, Baumgartner F, Braun L, O'Sullivan D, Thomas S, Waterhouse $\mathrm{M}$, et al. Sorafenib promotes graft-versus-leukemia activity in mice and humans through IL-15 production in FLT3-ITD-mutant leukemia cells. Nat Med. (2018) 24:282-91. doi: 10.1038/nm.4484

114. Romee R, Cooley S, Berrien-elliott MM, Westervelt P, Verneris MR, Wagner JE, et al. First-in-human phase 1 clinical study of the IL-15 superagonist complex ALT-803 to treat relapse after transplantation. Blood. (2018) 131:2515-28. doi: 10.1182/blood-2017-12-823757

115. Rutten CE, van Luxemburg-Heijs SA, Halkes CJ, van Bergen CA, Marjit EW, Oudshoorn M, et al. Patient HLA-DP-specific CD4+ T cells from HLADPB1-mismatched donor lymphocyte infusion can induce graft-versusleukemia reactivity in the presence or absence of graft-versus-host disease. Biol Blood Marrow Transpl. (2013) 19:40-8. doi: 10.1016/j.bbmt.2012.07.020

116. Petersdorf EW, Malkki M, O’hUigin C, Carrington M, Gooley T, Haagenson $\mathrm{MD}$, et al. High HLA-DP expression and graft-versus-host disease. $\mathrm{N}$ Engl J Med. (2019) 373:599-609. doi: 10.1056/NEJMoa1500140

117. Beyar-Katz O, Gill S. Novel approaches to acute myeloid leukemia immunotherapy. Clin Cancer Res. (2018) 24:5502-15. doi: 10.1158/1078-0432.CCR-17-3016

118. Jameson-Lee M, Koparde V, Griffith P, Scalora AF, Sampson JK, Khalid $\mathrm{H}$, et al. In silico derivation of HLA-specific alloreactivity potential from whole exome sequencing of stem-cell transplant donors and recipients: understanding the quantitative immunobiology of allogeneic transplantation. Front Immunol. (2014) 5:529. doi: 10.3389/fimmu.2014.00529

119. Martin PJ, Levine DM, Storer BE, Warren EH, Zheng X, Nelson SC, et al. Genome-wide minor histocompatibility matching as related to the risk of graft-versus-host disease. Blood. (2017) 129:791-8. doi: 10.1182/blood-2016-09-737700

120. Granados DP, Sriranganadane D, Daouda T, Zieger A, Laumont CM, CaronLizotte $\mathrm{O}$, et al. Impact of genomic polymorphisms on the repertoire of human MHC class I-associated peptides. Nat Commun. (2014) 5:1-14. doi: $10.1038 /$ ncomms 4600

121. van Els CACM, D’Amaro J, Pool J, Blokland E, Bakker A, van Elsen PJ, et al. Immunogenetics of human minor histocompatibility antigens: their polymorphism and immunodominance. Immunogenetics. (1992) 35:161-5. doi: 10.1007/BF00185109

122. van der Harst D, Goulmy E, Falkenburg JHF, Kooij-Winkelaar YMC, van Luxemburg-Heijis SAP, Goselink HM, et al. Recognition of minor histocompatibility antigens on lymphocytic and myeloid leukemic cells by cytotoxic T-cell clones. Blood. (1994) 83:1060-6. doi: 10.1182/blood.V83.4.1060.1060

123. den Haan JMM, Sherman NE, Blokland E, Huczko E, Koning F, Drijfhout JW, et al. Identification of a graft versus host disease-associated human minor histocompatibility antigen. Science. (1995) 268:1476-80. doi: $10.1126 /$ science.7539551

124. Oostvogels R, Lokhorst HM, Mutis T. Minor histocompatibility Ags: identification strategies, clinical results and translational perspectives. Bone Marrow Transplant. (2016) 51:163-71. doi: 10.1038/bmt.2015.256

125. Van Bergen CAM, Rutten CE, Van Der Meijden ED, Van Luxemburg-Heijis SAP, Lurvink EGA, Houwing-Duistermaat JJ, et al. High-throughput characterization of 10 new minor histocompatibility antigens by whole genome association scanning. Cancer Res. (2010) 70:9073-83. doi: 10.1158/0008-5472.CAN-10-1832 
126. Akatsuka Y, Nishida T, Kondo E, Miyazaki M, Taji H, Iida H, et al. Identification of a polymorphic gene, BCL2A1, encoding two novel hematopoietic lineage-specific minor histocompatibility antigens. J Exp Med. (2003) 197:1489-500. doi: 10.1084/jem.20021925

127. De Rijke B, van Horssen-Zoetbrood A, Beekman JM, Otterud B, Maas F, Woestenenk R, et al. A frameshift polymorphism in P2X5 elicits an allogeneic cytotoxic $\mathrm{T}$ lymphocyte response associated with remission of chronic myeloid leukemia. J Clin Invest. (2005) 115:3506-16. doi: 10.1172/JCI24832

128. Spierings E, Kim Y, Hendriks M, Borst E, Sergeant R, Canossi A, et al. Multicenter analyses demonstrate signi fi cant clinical effects of minor histocompatibility antigens on GvHD and GvL after HLA-matched related and unrelated. Biol Blood Marrow Transplant. (2013) 19:1244-53. doi: 10.1016/j.bbmt.2013.06.001

129. Marijt WAE, Heemskerk MHM, Kloosterboer FM, Goulmy E, Kester MGD, van der Hoorn MAWG, et al. Hematopoiesis-restricted minor histocompatibility antigens HA-1- or HA-2-specific T cells can induce complete remissions of relapsed leukemia. Proc Natl Acad Sci USA. (2003) 100:2742-7. doi: 10.1073/pnas.0530192100

130. Stern M, Passweg JR, Locasciulli A, Socie G, Schrezenmeier H, Bekassy AN, et al. Influence of donor/recipient sex matching on outcome of allogeneic hematopoietic stem cell transplantation for aplastic anemia. Transplantation. (2006) 82:218-26. doi: 10.1097/01.tp.0000226156.99206.d1

131. Randolph SSB, Gooley TA, Warren EH, Appelbaum FR, Riddell SR. Female donors contribute to a selective graft-versus-leukemia effect in male recipients of HLA-matched, related hematopoietic stem cell transplants. Blood. (2004) 103:347-53. doi: 10.1182/blood-2003-07-2603

132. Vogt MHJ, Paus RA De, Voogt PJ, Willemze R, Falkenburg JHF. DFFRY codes for a new human male-specific minor transplantation antigen involved in bone marrow graft rejection. Blood. (2000) 95:1100-6. doi: 10.1182/blood.V95.3.1100.003k42_1100_1105

133. Ofran Y, Kim HT, Brusic V, Blake L, Mandrell M, Wu C, et al. Diverse patterns of T-cell response against multiple newly identified human $\mathrm{Y}$ chromosome - encoded minor histocompatibility epitopes. Clin Cancer Res. (2010) 16:1642-52. doi: 10.1158/1078-0432.CCR-09-2701

134. Nakasone H, Tian L, Sahaf B, Kawase T, Schoenrock K, Perloff S, et al. Allogeneic HY antibodies detected 3 months after female-to-male HCT predict chronic GVHD and nonrelapse mortality in humans. Blood. (2015) 125:3193-201. doi: 10.1182/blood-2014-11-613323

135. Rizvi NA, Hellmann MD, Snyder A, Kvistborg P, Makarov V, Havel JJ, et al. Mutational landscape determines sensitivity to PD-1 blockade in non - small cell lung cancer. Science. (2016) 348:124. doi: 10.1126/science.aaa1348

136. The Cancer Genome Atlas Research Network. Genomic and epigenomic landscapes of adult de novo acute myeloid leukemia. N Engl J Med. (2013) 368:2059-74. doi: 10.1056/NEJMoa1301689

137. McGranahan N, Furness AJS, Rosenthal R, Ramskov S, Lyngaa R, Saini SK, et al. Clonal neoantigens elicit $\mathrm{T}$ cell immunoreactivity and sensitivity to immune checkpoint blockade. Science. (2016) 351:1463-9. doi: $10.1126 /$ science.aaf1490

138. Schischlik F, Jäger R, Rosebrock F, Hug E, Schuster M, Holly R, et al. Mutational landscape of the transcriptome offers putative targets for immunotherapy of myeloproliferative neoplasms. Blood. (2019) 134:199210. doi: 10.1182/blood.2019000519

139. van Rooij N, Van Buuren MM, Philips D, Velds A, Toebes M, Heemskerk $\mathrm{B}$, et al. Tumor exome analysis reveals neoantigen-specific T-cell reactivity in an ipilimumab-responsive melanoma. J Clin Oncol. (2013) 31:439-42. doi: 10.1200/JCO.2012.47.7521

140. Rajasagi M, Shukla SA, Fritsch EF, Keskin DB, DeLuca D, Carmona E, et al. Systematic identification of personal tumor-specific neoantigens in chronic lymphocytic leukemia. Blood. (2019) 124:453-63. doi: 10.1182/blood-2014-04-567933

141. Jurtz V, Paul S, Andreatta M, Marcatili P, Peters B, Nielsen M. NetMHCpan4.0: improved peptide- MHC class I Interaction predictions integrating eluted ligand and peptide binding affinity data. J Immunol. (2017) 199:33608. doi: 10.4049/jimmunol.1700893

142. Jensen KK, Andreatta M, Marcatili P, Buus S, Greenbaum JA, Yan Z, et al. Improved methods for predicting peptide binding affinity to MHC class II molecules. Immunology. (2018) 154:394-406. doi: 10.1111/imm.12889
143. Bentzen AK, Marquard AM, Lyngaa R, Saini SK, Ramskov S, Donia M, et al. Large-scale detection of antigen-specific T cells using peptide-MHCI multimers labeled with DNA barcodes. Nat Biotechnol. (2016) 34:1037-45. doi: $10.1038 /$ nbt.3662

144. Bjerregaard A, Nielsen M, Jurtz V, Barra CM, Eklund AC. An analysis of natural $\mathrm{T}$ cell responses to predicted tumor neopitopes. Front Immunol. (2017) 8:1566. doi: 10.3389/fimmu.2017.01566

145. Bjerregaard AM, Nielsen M, Hadrup SR, Szallasi Z, Eklund AC. MuPeXI: prediction of neo-epitopes from tumor sequencing data. Cancer Immunol Immunother. (2017) 66:1123-30. doi: 10.1007/s00262-017-2001-3

146. Van Buuren MM, Calis JJA, Schumacher TNM. High sensitivity of cancer exome-based CD8 T cell neo-antigen identification. Oncoimmunology. (2014) 3:e28836-1-6. doi: 10.4161/onci.28836

147. Yadav M, Jhunjhunwala S, Phung QT, Lupardus P, Tanguay J, Bumbaca $\mathrm{S}$, et al. Predicting immunogenic tumour mutations by combining mass spectrometry and exome sequencing. Nature. (2014) 515:572-6. doi: 10.1038 /nature14001

148. Gubin MM, Zhang X, Schuster H, Caron E, Ward JP, Noguchi T, et al. Checkpoint blockade cancer immunotherapy targets tumour-specific mutant antigens. Nature. (2014) 515:577-81. doi: 10.1038/nature13988

149. Anagnostou V, Smith KN, Forde PM, Niknafs N, Bhattacharya R, White J, et al. Evolution of neoantigen landscape during immune checkpoint blockade in non - small cell lung cancer. Cancer Discov. (2017) 7:264-77. doi: 10.1158/1538-7445.AM2017-NG01

150. Greiner J, Ono Y, Hofmann S, Schmitt A, Mehring E, Gotz M, et al. Mutated regions of nucleophosmin 1 elicit both CD4+ and CD8+ T-cell responses in patients with acute myeloid leukemia. Blood. (2012) 97:1282-90. doi: 10.1182/blood-2011-11-394395

151. Graf C, Heidel F, Tenzer S, Radsak MP, Solem FK, Britten CM, et al. A neoepitope generated by an FLT3 internal tandem duplication (FLT3-ITD) is recognized by leukemia-reactive autologous CD8+ T cells. Blood. (2007) 109:2985-9. doi: 10.1182/blood-2006-07-032839

152. Anguille S, Van Tendeloo VF, Berneman ZN. Leukemia-associated antigens and their relevance to the immunotherapy of acute myeloid leukemia. Leukemia. (2012) 26:2186-96. doi: 10.1038/leu.2012.145

153. Goswami M, Hensel N, Smith BD, Prince GT, Qin L, Levitsky HI, et al. Expression of putative targets of immunotherapy in acute myeloid leukemia and healthy tissues. Leukemia. (2014) 28:1167-70. doi: 10.1038/leu.2014.14

154. Zhao X, Chang Y, Huang X. Conflicting impact of alloreactive NK cells on transplantation outcomes after haploidentical transplantation : do the reconstitution kinetics of natural killer cells create these differences? Biol Blood Marrow Transplant. (2011) 17:1436-42. doi: 10.1016/j.bbmt.2011.05.020

155. Baron F, Petersdorf EW, Gooley T, Sandmaier BM, Malkki M, Chauncey $\mathrm{TR}$, et al. What is the role for donor natural killer cells after nonmyeloablative conditioning? Biol Blood Marrow Transpl. (2009) 15:5808. doi: 10.1016/j.bbmt.2009.01.018

156. Velardi A. Role of KIRs and KIR ligands in hematopoietic transplantation. Curr Opin Immunol. (2008) 20:581-7. doi: 10.1016/j.coi.2008.07.004

157. Karre K, Ljunggren HG, Piontek G, Kiessling R. Selective rejection of H-2deficient lymphoma variants suggests alternative immune defence strategy. Nature. (1986) 319:675-8. doi: 10.1038/319675a0

158. Angell TE, Lechner MG, Jang JK, LoPresti JS, Epstein AL. MHC class I loss is a frequent mechanism of immune escape in papillary thyroid cancer that is reversed by interferon and selumetinib treatment in vitro. Clin Cancer Res. (2014) 20:6034-44. doi: 10.1158/1078-0432.CCR-14-0879

159. del Campo A, Kyte JA, Carretero J, Zinchencko S, Mendez R, GonzalezAseguinolaza G, et al. Immune escape of cancer cells with beta2microglobulin loss over the course of metastatic melanoma. Int J Cancer. (2014) 113:102-13. doi: 10.1002/ijc.28338

160. Seliger B, Jasinski-Bergner S, Quandt D, Stoehr C, Bukur J, Wach S, et al. HLA-E expression and its clinical relevance in human renal cell carcinoma. Oncotarget. (2016) 7:67360-72. doi: 10.18632/oncotarget.11744

161. Ruggeri L, Capanni M, Urbani E, Perruccio K, Shomchik WD, Tosti $A$, et al. Effectiveness of donor natural killer cell alloreactivity in mismatched hematopoietic transplants. Science. (2002) 295:2097-100. doi: 10.1126/science.1068440 
162. Venstrom J, Pittari G, Gooley T, Chewning JH, Spellman S, Haagenson M, et al. HLA-C-dependent prevention of leukemia relapse by donor activating KIR2DS1. N Engl J Med. (2012) 367:805-16. doi: 10.1056/NEJMoa1200503

163. Walter RB, Gyurkocza B, Storer BE, Godwin CD, Pagel JM, Buckley SA, et al. Comparison of minimal residual disease as outcome predictor for AML patients in first complete remission undergoing myeloablative or nonmyeloablative allogeneic hematopoietic cell transplantation. Leukemia. (2015) 29:137-44. doi: 10.1038/leu.2014.173

164. Anthias C, Dignan FL, Morilla R, Morilla A, Ethell ME, Potter MN, et al. Pre-transplant MRD predicts outcome following reduced-intensity and myeloablative allogeneic hemopoietic SCT in AML. Bone Marrow Transplant. (2014) 49:679-83. doi: 10.1038/bmt.2014.9

165. Canaani J, Labopin M, Huang XJ, Ciceri F, Van Lint MT, Bruno B, et al. Minimal residual disease status predicts outcome of acute myeloid leukaemia patients undergoing T-cell replete haploidentical transplantation. An analysis from the Acute Leukaemia Working Party (ALWP) of the European Society for Blood and Marrow Transp. Br J Haematol. (2018) 183:411-20. doi: 10.1111/bjh.15540

166. Schmid C, Labopin M, Nagler A, Niederwieser D, Castagna L, Tabrizi R, et al. Treatment, risk factors, and outcome of adults with relapsed AML after reduced intensity conditioning for allogeneic stem cell transplantation. Blood. (2012) 119:1599-606. doi: 10.1182/blood-2011-08-375840

167. Craddock C, Labopin M, Robin M, Finke J, Chevallier P, Yakoub-Agha I, et al. Clinical activity of azacitidine in patients who relapse after allogeneic stem cell transplantation for acute myeloid leukemia. Haematologica. (2016) 101:879-83. doi: 10.3324/haematol.2015.140996

168. de Lima M, Oran B, Champlin RE, Papadopoulos EB, Giralt SA, Scott BL, et al. CC-486 maintenance after stem cell transplantation in patients with acute myeloid leukemia or myelodysplastic syndromes. Biol Blood Marrow Transplant. (2018) 24:2017-24. doi: 10.1016/j.bbmt.2018.06.016

169. AMADEUS: A Double-blind, Phase III, Randomised Study to Compare the Efficacy and Safety of Oral Azacitidine (CC-486) Versus Placebo in Subjects with Acute Myeloid Leukaemia (AML) or Myelodysplastic Syndromes (MDS) as Maintenance after Allogeneic Haematopo.Available online at: https://www. impactpartnership.org.uk/the-trials/amadeus/ (accessed July 25, 2019).

170. Goodyear O, Agathanggelou A, Novitzky-Basso I, Siddique S, McSkeane T, Ryan G, et al. Induction of a CD8+ T-cell response to the MAGE cancer testis antigen by combined treatment with azacitidine and sodium valproate in patients with acute myeloid leukemia and myelodysplasia. Blood. (2009) 116:1908-19. doi: 10.1182/blood-2009-11-249474

171. De Freitas T De, Marktel S, Piemontese S, Carrabba MG, Tresoldi C, Messina $\mathrm{C}$, et al. High rate of hematological responses to sorafenib in FLT3-ITD acute myeloid leukemia relapsed after allogeneic hematopoietic stem cell transplantation. Eur J Hematol. (2015) 96:629-36. doi: 10.1111/ejh.12647

172. Metzelder SK, Schroeder T, Finck A, Scholl S, Fey M, Gotze K, et al. High activity of sorafenib in FLT3-ITD-positive acute myeloid leukemia synergizes with allo-immune effects to induce sustained responses. Leukemia. (2012) 26:2353-9. doi: 10.1038/leu.2012.105

173. Rautenberg C, Germing U, Haas R, Kobbe G, Schroeder T. Relapse of acute myeloid leukemia after allogeneic stem cell transplantation: prevention, detection, and treatment. Int J Mol Sci. (2019) 20:1-20. doi: 10.3390/ijms20010228

174. Cortes JE, Khaled S, Martinelli G, Perl AE, Ganguly S, Russell N, et al. Quizartinib versus salvage chemotherapy in relapsed or refractory FLT3ITD acute myeloid leukaemia (QuANTUM-R): a multicentre, randomised, controlled, open-label, phase 3 trial. Lancet Oncol. (2019) 20:984-97. doi: 10.1016/S1470-2045(19)30150-0

175. A Trial of the FMS-like Tyrosine Kinase 3 (FLT3) Inhibitor Gilteritinib Administered as Maintenance Therapy Following Allogeneic Transplant for Patients With FLT3/Internal Tandem Duplication (ITD) Acute Myeloid Leukemia (AML). Available online at: https://clinicaltrials.gov/ct2/show/ NCT02997202 (accessed October 1, 2019).

176. DiNardo CD, Stein EM, de Botton S, Robiz GJ, Altman JK, Mims AS, et al. Durable remissions with ivosidenib in $I D H 1$-mutated relapsed or refractory AML. N Engl J Med. (2018) 378:2386-98. doi: 10.1056/NEJMoa1716984
177. Stein EM, DiNardo CD, Pollyea DA, Fathi AT, Roboz GJ, Altman JK, et al. Enasidenib in mutant IDH2 relapsed or refractory acute myeloid leukemia. Blood. (2017) 130:722-31. doi: 10.1182/blood-2017-04-779405

178. Ivosidenib as Maintenance Therapy in Treating Patients with IDH1mutant Acute Myeloid Leukemia, Myelodysplastic Syndrome, or Chronic Myelomonocytic Leukemia following Stem Cell Transplant. Available online at: https://www.cancer.gov/about-cancer/treatment/clinical-trials/search/v? $\mathrm{id}=$ NCI-2018-03528\&r=1 (accessed October 1, 2019).

179. IDH2 Inhibition Using Enasidenib as Maintenance Therapy for IDH2mutant Myeloid Neoplasms Following Allogeneic Stem Cell Transplantation. Available online at: https://clinicaltrials.gov/ct2/show/NCT03515512 (accessed October 1, 2019).

180. Motzer RJ, Rini BI, McDermott DF, Redman BG, Kuzel TM. Nivolumab for metastatic renal cell carcinoma : results of a randomized phase II trial. J Clin Oncol. (2015) 33:1430-7. doi: 10.1200/JCO.2014.59.0703

181. Royal RE, Levy C, Turner K, Mathur A, Hughes M, Kammula US, et al. Phase 2 trial of single agent ipilimumab (Anti-CTLA-4) for locally advanced or metastatic pancreatic adenocarcinoma. J Immunother. (2010) 33:828-33. doi: 10.1097/CJI.0b013e3181eec14c

182. Schadendorf D, Hodi FS, Robert C, Weber JS, Margolin K, Hamid O, et al. Pooled analysis of long-term survival data from phase II and phase III trials of ipilimumab in unresectable or metastatic melanoma. J Clin Oncol. (2015) 33:1889-94. doi: 10.1200/JCO.2014.56.2736

183. Ijaz A, Khan AY, Malik SU, Faridi W, Fraz MA, Usman M, et al. Biology of blood and marrow transplantation significant risk of graftversus-host disease with exposure to checkpoint inhibitors before and after allogeneic transplantation. Biol Blood Marrow Transplant. (2019) 25:94-9. doi: 10.1016/j.bbmt.2018.08.028

184. Merryman RW, Kim HT, Zinzani PL, Carlo-Stella C, Ansell SM, Perales $\mathrm{M}-\mathrm{A}$, et al. Safety and efficacy of allogeneic hematopoietic stem cell transplant after PD-1 blockade in relapsed/refractory lymphoma. Blood. (2017) 129:1380-8. doi: 10.1182/blood-2016-09-738385

185. Cilloni D, Saglio G. WT1 as a universal marker for minimal residual disease detection and quantification in myeloid leukemias and in myelodysplastic syndrome. Acta Haematol. (2004) 112:79-84. doi: 10.1159/000077562

186. Brayer J, Lancet JE, Powers J, List A, Balducci L, Komrokji R, et al. WT1 vaccination in AML and MDS: a pilot trial with synthetic analog peptides. (2015) 90:602-607. doi: 10.1002/ajh.24014

187. Maslak PG, Dao T, Bernal Y, Chanel SM, Zhang R, Frattini M, et al. Phase 2 trial of a multivalent WT1 peptide vaccine (galinpepimut$\mathrm{S})$ in acute myeloid leukemia. Blood Adv. (2018) 2:224-34. doi: 10.1182/bloodadvances.2017014175

188. Chapuis AG, Egan DN, Bar M, Schmitt TM, McAfee MS, Paulson $\mathrm{KG}$, et al. $\mathrm{T}$ cell receptor gene therapy targeting WT1 prevents acute myeloid leukemia relapse post-transplant. Nat Med. (2019) 25:1064-72. doi: 10.1038/s41591-0190472-9

189. Guy DG, Uy GL. Bispecific antibodies for the treatment of acute myeloid leukemia. Curr Hematol Malig Rep. (2018) 13:417-25. doi: $10.1007 /$ s11899-018-0472-8

190. Tasian SK. Acute myeloid leukemia chimeric antigen receptor Tcell immunotherapy : how far up the road have we traveled? Ther Adv Hematol. (2018) 9:135-48. doi: 10.1177/20406207187 74268

Conflict of Interest: The authors declare that the research was conducted in the absence of any commercial or financial relationships that could be construed as a potential conflict of interest.

Copyright (c) 2019 Sweeney and Vyas. This is an open-access article distributed under the terms of the Creative Commons Attribution License (CC BY). The use, distribution or reproduction in other forums is permitted, provided the original author(s) and the copyright owner(s) are credited and that the original publication in this journal is cited, in accordance with accepted academic practice. No use, distribution or reproduction is permitted which does not comply with these terms. 